\title{
LA PROTECCIÓN DE LAS MINORÍAS: UN DESAFÍO EN CLAVE DE CONSTITUCIONALISMO MULTINIVEL
}

DIANA SAYAGO ARMAS 
SUMARIO

I. INTRODUCCIÓN. I.A. Concepto de pueblos indígenas. I.B. Concepto de minorías nacionales. I.C. Minorías étnicas y minorías o pueblos indígenas. I.D. Balance conceptual. II. TIPOLOGÍA DE LOS GRUPOS: CLASIFICACIÓN DE LAS MINORÍAS. III. ESTATUTO JURÍDICO DE LOS GRUPOS. III.A. Marco normativo internacional. III.A.1. Naciones Unidas: especial referencia al Pacto Internacional de Derechos Civiles y Políticos de 1966. III.A.2.Convenio Europeo de Derechos Humanos (Convenio de Roma). III.A.3. Carta Social Europea. III.A.4. Carta Europea de Lenguas Regionales o Minoritarias. III.A.5. Convenio Marco para la Protección de las Minorías Nacionales. III.A.6. La Unión Europea. III.A.7.La Organización para la Seguridad y la Cooperación en Europa (OSCE). III.B. Balance sobre los instrumentos europeos. IV. RECONOCIMIENTO Y PROTECCIÓN DE LAS MINORÍAS EN ESPAÑA. IV.A. Comunidad Roma/gitana. V. CONCLUSIONES. 


\title{
LA PROTECCIÓN DE LAS MINORÍAS: UN DESAFÍO EN CLAVE DE CONSTITUCIONALISMO MULTINIVEL
}

\author{
DIANA SAYAGO ARMAS ${ }^{1}$
}

\section{INTRODUCCIÓN}

La definición del término "minorías" no es pacífica. La complejidad que entraña la elaboración jurídica del concepto ha supuesto un escollo aún no resuelto que choca insistentemente con una realidad que insiste en demandar una mayor concreción jurídica. Efectivamente, en las sociedades actuales la población no es homogénea, lo que obliga a los Estados democráticos a que procedan a una amplia revisión y refuerzo en el reconocimiento y protección de las libertades y el pluralismo. Es esta una asunción a todos los niveles que supone un avance aún por afianzar pero que sometido a un análisis en perspectiva histórica nos hace enjuiciarlo con una cierta dosis de indulgencia.

Para obtener un correcto encuadre en esta materia, es sin duda recomendable no perder de vista los múltiples factores relevantes que influyen en la consideración de los grupos humanos, entre los que se identifica con facilidad tanto el contexto político en el que se desarrolla el debate como la omnipresencia del elemento emotivo, que condiciona la aproximación y gestión de la diversidad. No cabe duda de que, en la actualidad, la pluralidad identitaria y cultural se acepta como algo positivo que todo Estado debe proteger dentro de su espacio territorial y demográfico, lo que ha impulsado una concepción más amplia e integradora de la democracia que supera - $-\mathrm{y}$ desborda - la aceptada hasta ahora. Y esto se asume en clave social, política y jurídica, como un reto de constitucionalismo multinivel.

El primer escollo se encuentra en la asunción de un concepto unívoco y generalmente aceptado, así como la correcta determinación de su definición. Desde los inicios

${ }^{1}$ Doctora en Derecho. Programa de Doctorado en Unión Europea. Escuela Internacional de Doctorado. Universidad Nacional de Educación a Distancia (UNED). Facultad de Derecho. Obispo Trejo, 2. 28040 Madrid. Email: anaidsayar@hotmail.com 
del siglo XX se observan esfuerzos por adoptar el concepto de minoría como término omnicomprensivo que engloba el fenómeno de la diversidad en los Estados, sin que se haya alcanzado un consenso ni en Derecho Internacional ni en la doctrina ${ }^{2}$. Los textos internacionales enmarcan su regulación en el contexto de la protección internacional de los derechos humanos ${ }^{3}$, pero distinguiendo y utilizando voces como "pueblo", "pueblo indígena" o "minorías nacionales o étnicas, lingüísticas y religiosas" . El Pacto Internacional de Derechos Civiles y Políticos de 1966 y la Declaración sobre los Derechos de las Personas Pertenecientes a Minorías Nacionales o Étnicas, Religiosas o Lingüísticas de 1992 recogen la expresión "minoría nacional o étnica, lingüística y religiosa”, mientras el Convenio Marco para la Protección de las Minorías Nacionales de 1995, en vigor desde 1998, se decanta por el uso del término más generalista “minorías nacionales”. En los documentos de la Unión Europea “minoría nacional" es la voz escogida como concepto que comprende a las minorías étnicas, religiosas o lingüísticas ${ }^{5}$. Mientras, en los documentos de Naciones Unidas observamos una equiparación de las expresiones "minoría nacional" y "minoría étnica", empero los Estados, en clave interna, apenas utilizan el término "minoría nacional"?

En Derecho constitucional comparado son cuatro los tipos de minorías que explícitamente se mencionan en los textos constitucionales europeos: esto es, las minorías

${ }^{2}$ SUÁREZ PERTIERRA, G., SOUTO GALVÁN, E., CIÁURRIZ LABIANO, M.J., , "Derecho $y$ minorías", UNED, Madrid, 2014, pág. 36: "(...) en los más recientes documentos internacionales se dudó entre el uso de las voces "comunidades", "grupos sociales", "pueblos", "grupos", y que la adopción final de la expresión minoría, tanto en el Pacto Internacional como en la Declaración (de 1966 y 1948, respectivamente), no resuelve, sin embargo, el problema conceptual, puesto que no se define en ninguno de los textos el significado de minoría".

${ }^{3}$ Sirva como ejemplo el art. 1 del Convenio Marco sobre Protección de las Minorías Nacionales, que proclama: "La protección de las minorías nacionales y de los derechos y libertades de las personas pertenecientes a esas minorías forma parte integral de la protección de los derechos humanos, y como tal entra dentro del ámbito de la cooperación internacional".

${ }^{4}$ RUIZ VIEYTEZ, E.J., GONZÁLEZ HIDALGO, E., "La definición implícita del concepto de minoría nacional en el Derecho Internacional”, Revista Derechos y Libertades, Número 27, Época II, junio 2012, pág. 21.

5 PENTASSUGLIA, G., "Minorities in international Law. An introductory study", Council of Europe Publishing, Alemania, 2002, pág. 63. Por su parte, Díaz Pérez de Madrid señala que en el marco europeo, con la expresión "minorías nacionales" no se hace referencia "a la diversidad cultural fruto de la inmigración —una fuente de diversidad que sí ha sido objeto de atención comunitaria desde distintos puntos de vista: libre circulación de trabajadores; visados, asilo e inmigración; o acuerdos de asociación, por ejemplo-, sino a la existencia de: Grupos numéricamente inferiores al resto de la población del Estado, en situación no dominante, cuyos miembros poseen características culturales propias (nacionales, étnicas, religiosas, lingüísticas), distintas a las de la mayoría en el Estado y que desean conservar, y que se encuentran generalmente en situación de tener un Estado-afín y/o encontrarse en situación especialmente vulnerable". (Díaz Pérez de Madrid, A., "Minorías y Unión Europea: implicaciones jurídico-políticas de la ampliación de la Unión al centro y este de Europa", Revista de Derecho Comunitario Europeo, $\mathrm{n}^{\circ}$ 21, Madrid, 2005, págs. 485-533).

${ }^{6}$ MARIÑO MENÉNDEZ, F., "Desarrollos recientes en la protección internacional de los derechos de las minorías y de sus miembros", en L. PRIETO SANCHÍs, (coord.), "Tolerancia y minorías. Problemas jurídicos de las minorías en Europa", Universidad de Castilla- La Mancha, Cuenca, 1996, pág. 77.

7 ARP, B., "Las minorías nacionales y su protección en Europa", Cuadernos y Debates, no 181, Centro de Estudios Políticos y Constitucionales, Madrid, 2008. 
lingüísticas ${ }^{8}$, las religiosas ${ }^{9}$, las étnicas ${ }^{10}$ y las nacionales ${ }^{11}$, adoptándose así la tipología por la que opta las Naciones Unidas. La Constitución de Bélgica se refiere en su art. 11 a las "minorías filosóficas o ideológicas", siendo la única constitución europea que incluye un tipo de minorías diferente a las cuatro citadas.

Por su parte, otros Estados europeos han aprobado legislaciones específicas que aluden a las minorías nacionales (Polonia, Croacia, Lituania, Hungría, Moldavia, República Checa, Serbia, Ucrania o la Federación Rusa), a las minorías lingüísticas (Italia y Albania), o a minorías o grupos étnicos o raciales (Polonia, Austria, Alemania, Reino Unido, Hungría). Asimismo, el término "nacionalidad” es usado con normalidad por los gobiernos de Macedonia, Ucrania, Rusia, Lituania, Eslovenia, Serbia, Armenia o Letonia, así como otros países como Letonia, Suecia, Rusia, Noruega, Dinamarca o Finlandia han adoptado en sus legislaciones conceptos como "pueblo" o "pueblos indígenas"12.

Todas estas expresiones se utilizan sin que se aporte una definición clara, consensuada y unívoca, de manera que ha sido obligatorio intentar cubrir este vacío a través de un análisis exhaustivo y sistemático tanto de los textos normativos internacionales como de la práctica política y legislativa de los órganos e instituciones internacionales y estatales. Vamos, por tanto, a abordar los términos más utilizados tanto en los principales textos internacionales como en la práctica política generalizada, adoptando el referido enfoque de constitucionalismo multinivel.

8 La expresión “minorías lingüísticas” aparece en las Constituciones de Italia (art. 6), Suecia (cap. 1, art. 2.4) y Austria (art. 8).

9 Las "minorías religiosas" aparecen expresamente mencionadas en las Constituciones de Suecia (cap. 1, art. 2.4), Chipre (art. 2), Croacia (art. 41), Serbia (art. 27 de la Carta de Derechos), Albania (art. 10), Macedonia (art. 19) y Bulgaria (art. 13).

${ }^{10}$ La expresión "minorías étnicas” se encuentra en las Constituciones de Estonia (art. 50), Letonia (art. 114), Polonia (art. 35), República Checa (art. 25 de la Carta de Derechos), Hungría (arts. 32 y 68) y Suecia (cap. 1, art. 2.4). Expresiones que hacen referencia a este tipo de minorías como "grupos étnicos" o "comunidades étnicas" aparecen en las Constituciones de Eslovaquia (arts. 33 y 34), Lituania (art. 37), Eslovenia (arts. 61 y 64) y Bielorrusia (art. 14).

${ }^{11} \mathrm{La}$ expresión «minorías nacionales» aparece en las Constituciones europeas de Albania (art. 20), Armenia (art. 37), Croacia (art. 15), Eslovaquia (arts. 33 y 34), Hungría (arts. 32 y 68), Montenegro (art. 79), Polonia (art. 35), República Checa (art. 25 de la Carta de Derechos), Rumania (arts. 6 y 32 ), Serbia (arts. 47 a 57 de la Carta de Derechos) y Ucrania (arts. 10, 11 y 53). El concepto «grupos nacionales» es mencionado por la Constitución de Eslovenia (art. 61), mientras que la palabra «nacionalidades» aparece en las Constituciones de España (art. 2), Macedonia (art. 48) y Ucrania (Preámbulo).

12 RUIZ VIEYTEZ, E.J., "España y el Convenio Marco para la protección de las minorías nacionales: una reflexión crítica”, Revista Española de Derecho Internacional, Vol. LXVI/1 Madrid, enerojunio, 2014, pág. 60 .

N.o 106, septiembre-diciembre 2019, págs 199-250 


\section{I.A. Concepto de Pueblos Indígenas}

La definición de conceptos tan amplios como "pueblo" o "pueblo indígena" ha constituido una cuestión harto compleja: autores, organismos internacionales, así como los propios pueblos indígenas no han encontrado en la actualidad una conceptualización unánimemente satisfactoria. Es este un término, que al igual que todos los que aluden a la diversidad, se ve condicionado por esa sensibilidad emocional que condena la tarea irremediablemente a la no asunción de un contenido taxativo. No obstante, se suele acudir a tres textos de carácter internacional ante la ausencia de una definición consensuada que otorgue un contenido concreto a la expresión "pueblos indígenas”. El primero de ellos fue elaborado por el Relator especial de Naciones Unidas de la Subcomisión de Prevención de la Discriminación y Protección de las Minorías, José Martínez Cobo, que elaboró entre 1981 y 1984 el "Estudio del problema de la discriminación contra las poblaciones indígenas". En dicho documento señala que "son comunidades, pueblos y naciones indígenas los que, teniendo una continuidad histórica con las sociedades anteriores a la invasión y las precoloniales que se desarrollaron en sus territorios, se consideran distintos de otros sectores de las sociedades que abora prevalecen en esos territorios o en partes de ellos. Constituyen abora sectores no dominantes de la sociedad y tienen la determinación de preservar, desarrollar y transmitir a futuras generaciones sus territorios ancestrales y su identidad étnica como base de su existencia continuada como pueblo, de acuerdo con sus propios patrones culturales, sus instituciones sociales y sus sistemas legales". Además, apuntó que persona indígena, es aquella "que pertenece a esas poblaciones indígenas por autoidentificación como tal indígena (conciencia de grupo) y es reconocida y aceptada por esas poblaciones como uno de sus miembros (aceptación por el grupo)".

La definición deja abierta la categorización al cumplimiento de una "continuidad histórica”"13, expresión que admite amplias interpretaciones. Por ejemplo, permite la inclusión de grupos que, aun cuando no conservan sus territorios ancestrales, preservan algún aspecto concreto que los distingue como indígenas frente a la sociedad dominante. De esta manera, se intenta abarcar todos aquellos grupos cuya evolución en el tiempo no ha sido uniforme en América Latina.

El segundo instrumento jurídico al que se suele acudir para dilucidar el concepto es el Convenio 169 sobre Pueblos Indígenas y Tribales en Estados Independientes de la Organización Internacional del Trabajo ${ }^{14}$. En su artículo 1 ya se definen los

${ }^{13}$ Los pueblos indígenas no constituyen comunidades que hayan permanecido inalterables en el tiempo. "Son grupos humanos dinámicos, que se reconfiguran a lo largo del tiempo con base en los rasgos culturales que les caracterizan. (...) En este sentido, la CIDH ha reconocido, por ejemplo, que en Guatemala los pueblos indígenas, pese a la discriminación étnica a la que históricamente han estado sujetos, "mantienen en todas las regiones, una actividad y organización social intensa y una cultura rica y en continua adaptación a las exigencias de los cambios históricos defendiendo y desarrollando su identidad cultural" [CIDH, Quinto Informe sobre la Situación de los Derechos Humanos en Guatemala. Doc. OEA/Ser.L/V/II.111, Doc. 21 rev., 6 de abril de 2001, Capítulo XI, párr. 4).

14 El Convenio 169 de la OIT (1989) tuvo un enorme impacto en la llamada "cuarta ola de Constituciones" (Jan-Erik Lane, en Van Cott, D.L., "The friendly liquidation of the past. The politics of 
caracteres de los “pueblos indígenas”, distinguiendo entre éstos y los “pueblos tribales” y adjudicándoles los mismos derechos a ambos:

“a) Pueblos tribales en países independientes, cuyas condiciones sociales, económicas y culturales les distingan de otros sectores de la colectividad nacional, y que estén regidos total o parcialmente por sus propias costumbres o tradiciones o por una legislación especial.

b) Pueblos en países independientes, considerados indígenas por el hecho de descender de poblaciones que habitan en el país o en una región geográfica a la que pertenece el país en la época de la conquista o la colonización o del establecimiento de las actuales fronteras estatales y que, cualquiera que sea su situación jurídica, conservan todas sus propias instituciones sociales, económicas, culturales y políticas, o parte de ellas".

De igual manera, el artículo 3 señala que "pueblos" "no deberá interpretarse en el sentido de que tenga implicación alguna en lo que atañe a los derechos que pueda conferirse a dicho término en el derecho internacional", ya que, entre las diferentes acepciones que se utilizan normalmente, se encuentran la que hace referencia a todos los habitantes del territorio de un Estado, sin distinción, o la que la relaciona con los habitantes de un pueblo no autónomo ("pueblos colonizados") $)^{15}$.

En conformidad a los artículos 1.1.(a) del Convenio $\mathrm{N}^{\circ} 169$ de la OIT y otros instrumentos internacionales, la Corte Interamericana de Derechos Humanos ha entendido que un pueblo tribal es "un pueblo que no es indígena a la región (que habita), pero que comparte características similares con los pueblos indígenas, como tener tradiciones sociales, culturales y económicas diferentes de otras secciones de la comunidad nacional, identificarse con sus territorios ancestrales y estar regulados, al menos en forma parcial, por sus propias normas, costumbres o tradiciones" $"$.

Como tercer instrumento normativo podemos citar el documento elaborado por la Relatora Especial de la Subcomisión de Prevención de la Discriminación y Protección de las Minorías y Presidenta del Grupo de Trabajo sobre Poblaciones Indígenas, Erica-Irene Daes, (E/CN.4/Sub.2/AC.4/1996/2). El Documento coincide con los dos anteriores en la descripción de sus caracteres pero suma un nuevo: la existencia de una

diversity in Latin America", University of Pittsburg Press, 2000, pág. 11). Las reformas constitucionales realizadas en Latinoamérica, ya fuera por la aprobación de nuevas constituciones o a través de enmiendas a las vigentes, fueron consecuencia de la aprobación del Convenio 169, siendo la lista extensa: Argentina (1994), el Estado Plurinacional de Bolivia (1994, 2004, 2009), Brasil (1988-2005), Colombia (1991; 2003); Costa Rica (1999), Ecuador (1996, 1998, 2008); El Salvador (1983-2000), Guatemala (19851998), Honduras (1982-2005), México (1992, 1994-1995, 2001), Nicaragua (1987, 1995, 2005), Panamá (1972; 1983; 1994), Perú (1993, 2005), Paraguay (1992) y Venezuela (1999). Van Cott llamó a este fenómeno "constitucionalismo multicultural" (2000, pág. 269). No obstante, no parece haberse traducido en una mejora apreciable en la calidad de vida de los indígenas.

15 PENTASSUGLIA, G., "Minorities in international Law. An introductory study", Council of Europe Publishing, Alemania, 2002, pág. 163; ARP, B., "Las minorías nacionales y su protección en Europa”, Centro de Estudios Políticos y Constitucionales, Madrid, 2008, pág. 128. Región (26).

${ }^{16}$ Corte IDH. Caso del Pueblo Saramaka Vs. Surinam. Excepciones Preliminares, Fondo, Reparaciones y Costas. Sentencia de 28 de noviembre de 2007. 
experiencia de subyugación, marginación, despojo, exclusión o discriminación, independientemente de que persistan actualmente. De esta manera, se acoge en el marco del concepto a los pueblos indígenas de América latina que durante los procesos de conquista sufrieron la represión, exclusión y marginación de sus miembros.

Los tres textos normativos citados eluden acudir únicamente a criterios lingüísticos o étnicos para calificar al grupo indígena, optándose por el principio subjetivo de la autoadscripción o autodefinición como elemento adicional determinante en la categorización. Asimismo, los grupos deben haber existido en el área que se trate con anterioridad al grupo dominante actual, subsistiendo (aún cuando éstas hayan evolucionado con el tiempo) sus singularidades propias de vida, sean de la índole que sea. Este va a ser un elemento diferencial crucial respecto al término "minorías", ya que con la minoría se puede hacer referencia a grupos que han podido asentarse en el territorio de un Estado con posterioridad al grupo dominante.

No obstante, a estos tres documentos es necesario añadir actualmente un último de gran trascendencia: la "Declaración sobre los Derechos de Pueblos Indígenas", aprobada el 13 de septiembre de 2007 por la Asamblea General de Naciones Unidas tras 22 años de elaboraciones y debates. El texto positiva un marco universal de estándares mínimos de derechos que se reconoce a los pueblos indígenas y que afecta a cinco ámbitos fundamentales: a) el derecho a la no discriminación; b) el derecho al desarrollo y bienestar social; c) el derecho a la integridad cultural; d) el derecho a la propiedad, acceso, uso y control de las tierras, territorios y recursos naturales, y e) el derecho a la participación política y al consentimiento libre, previo e informado. El artículo 42 establece la obligación de que Naciones Unidas promueva el respeto, la plena aplicación y la eficacia de las disposiciones de la Declaración, así como el Foro Permanente para las Cuestiones Indígenas, los organismos especializados y los Estados.

Es indiscutible la importancia e incuestionable el valor humano de todos los instrumentos normativos señalados. No obstante y pese a ello, la auténtica efectividad real no será lograda sin la firme adopción a nivel interno de disposiciones específicas que los desarrollen, así como la puesta en marcha de políticas activas cuyo paso previo sea la clarificación sin ambages de su ámbito de aplicación. Todo ello supone no solo una determinación concluyente en la protección y supervivencia de estos grupos más allá de otros intereses económicos y políticos imperantes, sino un esfuerzo adicional que se traduce en la utilización de recursos estatales de forma efectiva.

Al respecto, en América Latina algunos gobiernos han asumido en sus legislaciones internas definiciones que tienen en cuenta diversos criterios. La Ley Indígena de Chile (Ley Núm. 19.253) de 1993 estima circunstancias objetivas, socioculturales y de descendencia para su identificación, así como un elemento subjetivo de la autoidentificación. En el párrafo $2^{\circ}$ que denomina "De la calidad de Indígena", el artículo $2^{\circ}$ recoge que se considerarán indígenas "las personas de nacionalidad chilena (...): a) (...) que sean hijos de padre o madre indígena, cualquiera sea la naturaleza de su filiación, inclusive la adoptiva; Se entenderá por hijos de padre o madre indígena a quienes desciendan de babitantes originarios de las tierras identificadas en el Articulo 12, núm. 1 y 2. b) Los 
descendientes de las etnias indígenas que habitan el territorio nacional, siempre que posean a lo menos un apellido indígena. Un apellido no indígena será considerado indígena, para los efectos de esta ley, si se acredita su procedencia indígena por generaciones y c) Los que mantengan rasgos culturales de alguna etnia indígena, entendiéndose por tales la práctica de formas de vida, costumbres o religión de estas etnias de un modo habitual o cuyo cónyuge sea indígena. En estos casos, será necesario, además, que se autoidentifiquen como indígenas".

El párrafo $4^{\circ}$ del artículo $9^{\circ}$ reconoce como Comunidad indígena a "toda agrupación de personas pertenecientes a una misma etnia indígena y que se encuentren en una o más de las siguientes situaciones: a) Provengan de un mismo tronco familiar; b) Reconozcan una jefatura tradicional, c) Posean o bayan poseído tierras indígenas en común, y d) Provengan de un mismo poblado antiguo."

En Argentina, la Ley 23.302 (1985) de "Política Indígena y Apoyo a las comunidades Aborígenes" considera el criterio de la descendencia como definitorio y reconoce la personalidad jurídica de las comunidades (en su artículo $2^{\circ}$ ): "A los efectos de la presente ley, reconócese personería jurídica a las comunidades indígenas a los conjuntos de familias radicadas en el país. Se entenderá como comunidades indígenas a los conjuntos de familias que se reconozcan como tales por el hecho de descender de poblaciones de habitaban el territorio nacional en la época de la conquista o colonización e indígenas o indios a los miembros de dicha comunidad. La personería jurídica se adquirirá mediante la inscripción en el Registro de Comunidades Indígenas y se extinguirá mediante su cancelación".

En Paraguay, la Comunidad Indígena se define como "el grupo de familias extensas, clan o grupos de clanes, con cultura y un sistema de autoridad propios que hablan una lengua autóctona y convive en un hábitat común" (artículo $2^{\circ}$ de la Ley Núm. 904/81, Estatuto de Comunidades Indígenas de 1981). De esta forma, se exige la existencia de un sistema de autoridad propios, así como una lengua autóctona.

Pese a todo, no se puede afirmar que se hayan producido avances satisfactorios. Las reivindicaciones en este sentido, procedentes tanto de las comunidades indígenas como de los propios agentes políticos que exigen mayor efectividad e implicación, han continuado. Debemos tener en cuenta, que las propias organizaciones indígenas no consideran que su situación sea asimilable con la de las minorías. Como pueblos originarios, ellos insisten en sus derechos como víctimas de las invasiones y conquistas del pasado, de forma que sus demandas constituyen una devolución de derechos perdidos y no la protección de derechos otorgados. He aquí un factor importantísimo para el logro de la realización efectiva de las condiciones de vida en la diversidad: al igual que se considera necesario el deseo libre y expreso de adscripción del individuo al grupo para que se le otorgue protección como miembro del mismo (así se refleja en múltiples textos normativos) debemos aprender a escuchar "mejor" sus reivindicaciones para, dentro de los márgenes constitucionales, perfeccionar las estrategias de protección que deberán seguir implementándose hasta conseguir el fin deseado. 


\section{B. Concepto de Minorías Nacionales}

Los pueblos indígenas designan a un tipo de colectivos con una serie de características propias y determinadas. No obstante, "pueblos indígenas" hace referencia a una de las categorías en las que puede concretarse la realidad de la diversidad humana que, adelanto, se sitúa dentro del concepto global e integrador de la expresión "grupo".

Ya se ha señalado que no se utiliza una sola voz, y en este nominal desconcierto, es fácil encontrar el empleo de términos como "minorías nacionales" para abordar de manera generalista toda la realidad de las minorías. En los propios documentos de Naciones Unidas observamos una equiparación de las expresiones "minoría nacional" y "minoría étnica" 17 , sin que se determine un contenido definitorio, aunque revele cierta pretensión generalista. La doctrina, por su parte, ha intentado llenar el vacío conceptual sin que tampoco se haya alcanzado un resultado satisfactorio.

Se parte de la base de que la pertenencia a una minoría puede darse por razones de naturaleza (se pertenece a una raza y no es posible dejar de pertenecer), debido a una situación ocasional de la que es posible pero difícil separarse (la condición social), o bien encuentra su origen en una decisión personal que el individuo puede abandonar en cualquier momento (la adopción de una confesión religiosa) ${ }^{18}$. Asimismo, el elemento numérico suele ser definitivo para un amplio sector doctrinal, de manera que el colectivo debe ser inferior al resto de la población del Estado donde se integra. Packer señala que el número de personas que integran la minoría es relevante tanto para establecer la existencia del grupo, como para especificar los titulares de los derechos de protección que se establezcan ${ }^{19}$. Sin embargo, también se puede poner el énfasis en la posición no dominante del colectivo respecto al grupo mayoritario ${ }^{20}$, así como las características étnicas, religiosas o lingüísticas propias por las que se diferencian del resto de la población ${ }^{21}$. Ruiz Vieytez y González Hidalgo, por su parte, han

17 MARIÑO MENÉNDEZ, F., "Desarrollos recientes en la protección internacional de los derechos de las minorías y de sus miembros", en PRIETO SANCHÍS, L. (Coord.), "Tolerancia y minorías. Problemas jurídicos de las minorías en Europa", Universidad de Castilla- La Mancha, Cuenca, 1996, pág. 77.

18 SUÁREZ PERTIERRA, G., SOUTO GALVÁN, E., CIÁURRIZ LABIANO, M.J.,, "Derecho y minorías", UNED, Madrid, 2014, pág. 19.

19 PACKER, J., "Problems in Defining Minorities", en FOTTRELL, D. (Ed.), "Minority and Group Rights in the New Millennium”, Martinus Nijhoff, La Haya, 1999, pág. 260.

20 SORIANO, R., "Los derechos de las minorías", MAD, Sevilla, 1999, págs. 18-19. Por su parte, tanto Capotorti como Deschênes incluyen en sus definiciones el criterio de la "posición no dominante" del grupo con el objetivo de evitar que una minoría dominante y no vulnerable disfrutara de los derechos establecidos para la protección de las minorías nacionales, como podía darse en el caso del régimen racista instaurado en Sudáfrica. LIEBICH, A., "Les minorités nationales en Europe Centrale et Orientale, Institut Européen”, Université de Genève, Ginebra, 1997, pág. 17; L. PRIETO SANCHÍS, "Minorías, respeto a la diferencia e igualdad sustancial”, DOXA. Cuadernos de Filosofía del Derecho, núm. 15-16, 1994, pág. 368; NACIONES UNIDAS, Subcomisión de las Naciones unidas de Promoción y Protección de Derechos Humanos. E/CN.4/Sub.2/1985/SR.13, p. 8, párrafo 42.

${ }^{21}$ SOUTO PAZ, J.A., "Comunidad politica y libertad de creencias", Marcial Pons, Madrid, 2007. 
analizado la noción de "minorías nacionales" en el marco actual del Derecho europeo de las minorías y el Derecho Internacional de los Derechos Humanos, afirmando que la definición implícitamente aceptada en estos contextos normativos ${ }^{22}$ las conceptualiza como grupos de personas que se diferencian del resto de la población del Estado donde residen por razones étnicas, religiosas y lingüísticas, caracterizándose además, por ser numéricamente inferior y disponer de la nacionalidad jurídica de ese Estado. Asimismo, a esto se añade que los miembros que componen el grupo se autodefinen habitualmente como parte de ese grupo minoritario y manifiestan, aún de modo implícito, cierta voluntad colectiva de mantener y desarrollar su propia identidad ${ }^{23}$.

Efectivamente, a las notas características definitorias hay que añadir dos elementos subjetivos esenciales: la propia conciencia como grupo que ostentan sus miembros, cuya voluntad colectiva es la de permanencia y realización de su diferencia ${ }^{24}$. Sin la concurrencia de estos elementos subjetivos, la pretensión de protección no tendría lugar ni justificación. Parejo Alfonso, tras analizar el Informe Capotorti, incorpora ambas dimensiones para proporcionar una definición completa ${ }^{25}$, en la que distingue:

a) Elementos objetivos:

- Hecho diferencial: poseer una serie de características étnicas, lingüísticas o religiosas comunes.

- Número inferior, pero relevante.

— Estabilidad y permanencia en el tiempo dentro de una misma área.

- Posición no dominante.

- Ciudadanía (nacionalidad del Estado en que se encuentre).

b) Elementos subjetivos:

- Voluntad de ser y de manifestarse como minoría (con arreglo a criterios democráticos).

- Voluntad de afirmar y proteger el hecho diferencial.

- Deseo de mantener y continuar con las propias instituciones, tradiciones y lengua (es decir, de mantener la cultura propia).

${ }^{22}$ Ya que, como afirman los autores, "la noción de "minoría nacional" no está definida en ningún instrumento internacional de carácter universal”. (RUIZ VIEYTEZ, E.J., GONZÁLEZ HIDALGO, E., "La definición implícita del concepto de minoría nacional en el Derecho Internacional”, Revista Derechos y Libertades, Número 27, Época II, junio 2012, pág. 22).

${ }^{23}$ RUIZ VIEYTEZ, E.J., GONZÁLEZ HIDALGO, E., "La definición implícita del concepto de minoría nacional en el Derecho Internacional", Op. Cit., pág. 51.

${ }^{24}$ AÑÓN ROIG, M.J., "Ciudadanía diferenciada y derechos de las minorías", en DE LUCAS, J., "Derechos de las minorías en una sociedad multicultural", Consejo Editorial del Poder Judicial, Madrid, 1998, pág. 77.

25 PAREJO ALFONSO, L., Capítulo “Minorías y Constitución”, en RODRÍGUEZ PALOP, M.A., TORNOS A., "Derechos culturales y derechos bumanos de los inmigrantes", Universidad Pontificia de Comillas, Madrid, 2000, pág. 149. 
Mariño Menéndez adiciona otra característica más: el grupo debe encontrase en "situación de vulnerabilidad"26. La vulnerabilidad implica una situación de desprotección tal que apareja una desigualdad en la que el individuo ve disminuida su capacidad efectiva para ejercer sus derechos básicos y propios y, en paralelo, ve gravemente obstaculizadas sus capacidades y posibilidades para hacer frente a la lesión de estos derechos. Atendiendo a la concurrencia de esta situación de desigualdad, es común ver incluidos en la clasificación de las “minorías” a los niños, las mujeres ${ }^{27}$ y los ancianos. Efectivamente, este tipo de colectivos normalmente son destinatarios de múltiples medidas de acción positiva por parte de los poderes públicos. Lo mismo puede predicarse de las personas que se encuentran en grave riesgo de exclusión social como los presos, los drogadictos o los disminuidos físicos y psíquicos. Aun así, no se puede asimilar el concepto de minoría con este concepto de ciudadanía diferenciada del resto como consecuencia de una situación especial que se manifiesta en una desigualdad económica o social y que no conforman una categoría unitaria en sí misma por razones de tradición, costumbres, cultura, lengua o religión. No obstante, ni que decir tiene que los grupos humanos mencionados, deben ser destinatarios de las políticas adecuadas así como de los recursos oportunos para eliminar las desigualdades a las que se ven sometidos.

Debemos mencionar en este punto, el afianzamiento de otro colectivo presente en nuestra sociedad que reclama el reconocimiento y respeto de su diversidad ${ }^{28}$ en relación a su identidad sexual. Sus reivindicaciones se concretan en la lucha contra la discriminación, demandando la efectividad del derecho a la igualdad en ámbitos sanitarios, laborales y sociales ${ }^{29}$ y, en definitiva, el pleno disfrute de sus derechos

${ }^{26}$ MARIÑO MENÉNDEZ, F., "Introducción. Aproximación a la noción de persona y grupo vulnerable en el Derecho europeo", en "La protección de las personas y grupos vulnerables en el Derecho europeo", MARIÑO MENÉNDEZ, F., y FERNÁNDEZ LIESA, C. (Dirs. y Coords.), Universidad Carlos III de Madrid/ Ministerio de Trabajo y Asuntos Sociales, Madrid, 2001, pág. 21.

${ }_{27}$ Cuestión muy diferente es la situación aún más vulnerable que sufren las mujeres en el seno del grupo con respecto a los varones, situación que por motivos de extensión no será estudiado en este trabajo. Se recomienda la lectura de Shachar para profundizar en su problemática (SHACHAR A., "Multicultural Jurisdictions. Cultural Differences and Women's Rights", Cambridge University Press , 2001).

28 FLORES DÁVILA, J.L., "La diversidad sexual y los retos de la igualdad y la inclusion", Colección Estudios, Consejo Nacional para Prevenir la Discriminación” (CONAPRED), México, 2007, pág. 62: "Cada vez que se habla de diversidad sexual estamos diciendo homosexuales, lesbianas, heterosexuales, bisexuales, transgéneros y transexuales. Se trata a toda luz de un concepto que busca incluirnos a todos, de un concepto que habla de una sociedad que se da la posibilidad a sí misma de reconocer las distintas formas de intercambio afectivo o sexual que bay en su seno".

29 Al respecto, cada vez cobran mayor importancia los denominados Principios de Yogyakarta, principios sobre la aplicación de la legislación internacional de derechos humanos en relación con la orientación sexual y la identidad de género. Pretenden erigirse en el marco que sirva de base para evitar los abusos y dar protección a los derechos humanos de las personas lesbianas, gais, bisexuales y transexuales (LGTB). Sin embargo, y aunque los Principios de Yogyakarta fueron presentados el 26 de marzo de 2007 ante el Consejo de Derechos Humanos de las Naciones Unidas, en Ginebra, éstos no han sido ratificados por los Estados en un tratado, y por tanto no constituyen, por sí mismos, un instrumento vinculante en Derecho internacional. Asimismo, por su parte, el Consejo de Derechos Humanos, en su 
fundamentales en general. Sin embargo, tampoco considero que pueda incorporarse al concepto de "minoría" o "minoría nacional" por los mismos argumentos aludidos. La desigualdad fáctica que les impide u obstaculiza el ejercicio pleno de sus derechos, les convierte legítimamente en destinatarios de medidas de acción positiva por parte de los poderes públicos para paliar esta situación grave de desigualdad, pero no conforman una categoría unitaria en sí misma por razones de tradición, costumbres, lengua o religión.

El Derecho, entre cuyas obligaciones se encuentra proponer los instrumentos necesarios para la protección y realización del ser humano en su máxima expresión, tiene que identificar desde el primer momento la forma de vulneración y la desigualdad, así como su origen y causas, para poder proponer los recursos jurídicos procedentes y eficaces en la preservación y efectividad de los derechos del ser humano.

\section{I.C. Minorías Étnicas y Minorías o Pueblos Indígenas}

Llegados a este punto también se nos presenta otra cuestión: si es correcto considerar sinónimas las expresiones "minorías étnicas" y "minorías o pueblos indígenas". La palabra etnia deriva del griego ethnos, que significa precisamente "pueblo", siendo conceptualizada por la RAE como "comunidad bumana definida por afinidades raciales, lingüísticas, culturales, etc.". En la propuesta de un Protocolo adicional al Convenio Europeo de Derechos Humanos, presentada por el gobierno austriaco al Comité de Ministros del Consejo de Europa-el 20 de diciembre de 1991, el artículo $1^{\circ}$ definía la expresión "grupo étnico" como un colectivo de ciudadanos de un Estado que residen tradicionalmente sobre su territorio, siendo menos numeroso que el resto de la población de ese Estado o de una región del mismo y presentando características étnicas o

Resolución 17/19 de 2011 condena formalmente cualquier acto de violencia o discriminación por orientación sexual e identidad de género en cualquier parte del mundo. También prohíbe esa discriminación el artículo 21 de la Carta de Derechos Fundamentales de la Unión Europea. En el marco de la Unión Europea, podemos destacar tres directivas en este campo: 1) la Directiva 2006/54/CE del Parlamento y del Consejo, de 5 de julio, relativa a la aplicación del principio de igualdad de oportunidades e igualdad de trato entre hombres y mujeres en asuntos de empleo y ocupación.; 2) la Directiva 2004/113/CE del Consejo, de 13 de diciembre, por la que se aplica el principio de igualdad de trato entre hombres y mujeres al acceso de bienes y servicios y su suministro; y 3) la Directiva 2000/78/CE, del Consejo, de 27 de noviembre, relativa al establecimiento de un marco general para la igualdad de trato en el empleo y la ocupación. Por su parte, las resoluciones del Parlamento Europeo de 8 de febrero de 1994, de 18 de enero de 2006 y de 24 de mayo de 2012, garantizan la igualdad de derechos de lesbianas y gais y en la lucha contra la discriminación y la homofobia en el acceso al empleo. En cuanto a nuestro país, el 30 de junio de 2005 se aprobó una importante modificación del Código Civil que permitió el matrimonio de personas del mismo sexo, y como consecuencia de ello, otros derechos de envergadura como la adopción conjunta, la herencia y la pensión. Como ejemplo más reciente, en la Comunidad de Madrid, se ha aprobado la Ley 3/2016, de 22 de julio, de Protección Integral contra la LGTBifobia y la Discriminación por Razón de Orientación e Identidad Sexual.

N.o 106, septiembre-diciembre 2019, págs 199-250 
lingüísticas diferentes de las del resto de la población, conservando su propia identidad cultural ${ }^{30}$.

Al respecto, considero que tanto las minorías étnicas como las minorías indígenas hacen referencia a un grupo de personas que presenta características comunes propias, que se encuentra en una situación de subordinación, dependencia o de vulnerabilidad respecto del resto y que muestran la voluntad de conservar esas características propias que los identifican. Sin embargo, entre ambas realidades existe una diferencia determinante, esto es, la existencia del grupo en el área del territorio del Estado en el que se integran actualmente en un tiempo anterior al del grupo dominante o mayoritario, siendo más acertada la denominación de "pueblos indígenas" en este caso ${ }^{31}$. Todo esto en atención además a un elemento subjetivo que debemos tener en cuenta: los pueblos indígenas han manifestado en diversos foros internacionales el deseo de ser denominados de esta forma en contraposición a las expresiones "minorías indígenas" o "minorías étnicas"32.

\section{I.D. Balance conceptual}

Entre todas las acepciones analizadas, el término "grupos” es el que integra en su globalidad la realidad que nos ocupa. La expresión abarcaría el contenido conceptual de la "minoría" y de "pueblo" ${ }_{3}$, definiéndose como un conjunto de personas que comparten características identitarias comunes, diferentes al del resto de personas del Estado en el que habitan, respecto de las cuales se sitúan en una posición no dominante o subordinación que se traduce en una situación de vulnerabilidad de algún tipo. El trasfondo subjetivo que subyace al conjunto de sus miembros es una voluntad de mantener y desarrollar la propia identidad, cuestión que incide directamente en

${ }^{30}$ MADINABEITIA, X., "La Protección de las Minorías Nacionales en el Consejo de Europa", Instituto Vasco de Administración Pública, Bilbao, 2000, pág. 53.

${ }^{31}$ No todos los instrumentos internacionales sobre la protección de las personas pertenecientes a minorías nacionales imponen el criterio temporal en el territorio del Estado para ser apreciados como tales. Entre los documentos que si lo reclaman se encuentra la Resolución 1201 de la Asamblea Parlamentaria del Consejo de Europa. Por contra, el Convenio Marco para la Protección de las Minorías Nacionales en el artículo 14.2 incluye la alusión a "(...) las zonas geográficamente habitadas tradicionalmente (...)".

32 Declaraciones de Victoria Tauli-Corpuz, Relatora Especial de Naciones Unidas sobre los Derechos de Pueblos Indígenas, el 11 de mayo de 2015, en: http://unsr.vtaulicorpuz.org/site/index.php/ es/entrevistas-y-prensa/67-opinion-sdg: "Luchamos por el reconocimiento mundial de nuestros derechos en la Declaración de la ONU sobre los Derechos de los Pueblos Indígenas. Tuvimos que luchar para ser llamados "Pueblos Indígenas", un término que nos reconoce como pueblos con identidades distintas y culturas que tienen el derecho a la libre determinación".

${ }_{33}$ Natan Lerner propone utilizar el término "grupo" como concepto omnicomprensivo que englobaría a tribus, pueblos, minorías culturales o religiosas y naciones. Asimismo, expone una serie de derechos de grupo mínimos o estándar que deben reconocérsele a éstos, entre los que señala el derecho a la existencia y a la identidad, a la participación política, al uso de su lengua, o al establecimiento de instituciones propias. (LERNER N., "Group Rights and Discrimination in International Law", International Studies in Human Rights, Vol. 15, Dordrecht, Martinus Nijhoff, 1991, págs. 28-39). 
los derechos fundamentales de cada individuo que integra el colectivo y que deben ser garantizados en su ejercicio efectivo y pleno, de manera que el desafío que supone el perfeccionamiento y adaptación del libre desarrollo de la personalidad tiene en la gestión normativa de la diversidad uno de sus retos más importantes. La función del Derecho será imponer un efecto nivelador que realice la igualdad real en sociedades caracterizadas por una realidad que se ha denominado como una paulatina "pluralización democrática” ${ }^{34}$. Para ello, es necesario abordar la diferenciación entre minoría y pueblo, realidades que cuentan con muchos factores comunes, pero cuyas diferencias, una vez identificadas, facilitan la finalidad práctica e intrínseca que subyace en la regulación de la diversidad actual.

\section{TIPOLOGÍA DE LOS GRUPOS: CLASIFICACIÓN DE LAS MINORÍAS}

Las minorías, como categoría que se encuadra dentro de los grupos, también admite una clasificación que la doctrina se ha encargado de desarrollar (sin consenso) y que supone un estimable auxilio en la tarea de determinación y comprensión de la diversidad de estos grupos concretos que conforman las "minorías". Una acertada aproximación a ella nos la aporta la obra "Los derechos de las minorías" 35 , diferenciando entre las minorías nacionales, minorías étnicas o emigradas y las minorías sociales.

1) Minorías nacionales: constituidas por colectivos o comunidades asentadas en un territorio estatal o fronterizo. Se identifican, además, por poseer un patrimonio cultural propio por razón de su raza, lengua, religión, tradiciones, etc., y por estar en una grave situación de dependencia política respecto a una estructura de poder dominante. Como ejemplos se pueden citar los lapones en el norte de Europa. Esta división se subdivide, a su vez en: a) minorías que se localizan dentro del territorio de un Estado; b) minorías adyacentes al territorio de un Estado y formada por comunidades de dicho Estado; o c) minorías repartidas en los territorios de varios Estados y que pretenden constituir una comunidad y un Estado nuevo.

2) Minorías étnicas o emigradas: formadas por grupos de personas erradicadas de sus países de origen, que emigran voluntariamente a otros países o impelidas por circunstancias adversas. Estos grupos se esparcen normalmente por el territorio del Estado receptor y persiguen el reconocimiento de derechos de igualdad por encima de derechos de autonomía. Entre las minorías

34 RUIZ VIEYTEZ, E.J., "España y el Convenio Marco para la protección de las minorías nacionales: una reflexión crítica”, Revista Española de Derecho Internacional, Vol. LXVI/1 Madrid, enerojunio, 2014, pág. 57.

35 SUÁREZ PERTIERRA, G., SOUTO GALVÁN, E., CiÁURRIZ LABIANO, M.J., "Derecho y minorías", UNED, Madrid, 2014, págs. 19-20. 
nacionales y las minorías étnicas o emigradas se pueden situar los refugiados y los emigrantes forzosos. Sus reivindicaciones se aproximan a las de las minorías nacionales, solicitando mantener su identidad cultural.

3) Minorías sociales: son colectivos de ciudadanos de un Estado que se encuentran en una situación precaria que les obstaculiza o impide el disfrute de sus derechos y condiciones de vida reconocidos. Se consideran que pertenecen a este grupo los incapacitados, las personas en situación de precariedad económica, los internos de instituciones penitenciarias, etc. En mi opinión no pueden ser calificados de "minorías", en puridad. Las dos primeras clasificaciones pueden integrarse en el denominado fenómeno del multiculturalismo, siendo la tercera división una colectividad que plantea problemas de integración eminentemente diferentes pero que inciden directamente en una situación de desigualdad.

Will Kymlicka por su parte, identificó dos categorías amplias: las minorías nacionales y las minorías fruto de la inmigración individual y familiar ${ }^{36}$. Las primeras aparecen con la incorporación de culturas que previamente disfrutaban de autogobierno y se encuentran territorialmente concentradas en un Estado mayor. Sus reivindicaciones pasan por seguir siendo reconocidas como sociedades distintas respecto de la cultura mayoritaria para lo que exigen diversas formas de autonomía y autogobierno. En el segundo tipo, que Kymlicka denomina "grupos étnicos”, las minorías emergen ante la inmigración individual y familiar. Acostumbran a unirse en asociaciones poco rígidas donde existe el deseo de integrarse en la sociedad de la que forman parte como miembros de pleno derecho, sin que se obvie su reconocimiento étnico. No abogan por la concesión de derechos de autogobierno, sino alcanzar una legislación que sea respetuosa con las diferencias culturales.

Madinabeitia utiliza tres criterios para clasificar las minorías, según se atienda a sus características geográficas, a su origen, o su carácter sociológico ${ }^{37}$. Desde el punto de vista geográfico o espacial, distingue entre minorías dispersas y concentradas o territoriales, definiendo las dispersas como aquellas que no poseen una localización concreta (como los roma/gitanos), e identificando las concentradas como minorías que cuentan con un espacio o territorio determinado. Estas se subdividen a su vez en: a) minorías de madre patria, las cuáles se encuentran vinculadas con una comunidad mayoritaria de un Estado, generalmente vecino (por ejemplo, los húngaros de Eslovaquia y Rumania); y, b) nacionalidades, que constituyen minorías sin Estado propio (y que pueden residir en un único Estado, como los escoceses o los bretones, o residir en dos o más países, tal y como ocurre en el caso de kurdos o los vascos).

36 KYMLICKA, W., "Ciudadanía multicultural. Una teoría liberal de los derechos de las minorías", Paidós, Barcelona, 1996, págs. 25 y ss.

37 MADINABEITIA, X., "La Protección de las Minorías Nacionales en el Consejo de Europa", Instituto Vasco de Administración Pública, Bilbao, 2000, págs. 38-40. 
Según su origen, las minorías pueden dividirse en minorías históricas o nuevas minorías. Las primeras hacen referencia a aquellas que residen tradicionalmente en el territorio de un Estado mientras las segundas son las formadas como consecuencia de flujos migratorios más o menos recientes. Situadas en un nivel intermedio entre las minorías históricas y las recientes, se encuentran las minorías de historicidad relativa.

Desde un punto de vista sociológico, Madinabeitia distingue entre las minorías religiosas, las minorías lingüísticas y las minorías étnicas. Las primeras poseen unas creencias o prácticas religiosas diferentes a las de la mayoría de la población. Las segundas utilizan una lengua diferente a la utilizada por la mayoría de la población de un Estado. Por último, las minorías étnicas forman un etnia o una comunidad cultural diferente al resto de la población de un Estado.

No obstante, la clasificación de las minorías no sólo ha sido abordada por la doctrina: los instrumentos internacionales en la materia contemplan generalmente una clasificación, dividiéndolas normalmente en étnicas, religiosas, lingüísticas y nacionales. Como ejemplos podemos citar el Pacto Internacional sobre Derechos Civiles y Políticos de Naciones Unidas de 16 de diciembre 1966, cuyo artículo 27 hace alusión a minorías étnicas, lingüísticas y religiosas, así como el Convenio-Marco del Consejo de Europa de 1995, que clasifica a las minorías en étnicas, lingüísticas, religiosas y nacionales. Por su parte, la Resolución 47/135 de 1992 de la Organización de las Naciones Unidas se refiere expresamente a las minorías nacionales o étnicas, religiosas y lingüísticas. Por tanto y generalizando: con la finalidad de abordar a continuación el marco jurídico de los grupos podemos afirmar que mayoritariamente tanto en Derecho Constitucional Comparado, como en el ámbito de Naciones Unidas y los demás organismos internacionales, la clasificación expresamente recogida es la que diferencia entre minorías étnicas, religiosas, lingüísticas y nacionales. Esta diferenciación en los textos normativos aparece con un aura complaciente de "vocación definitoria”, en ausencia de una auténtica conceptualización.

\section{III.ESTATUTO JURÍDICO DE LOS GRUPOS: MINORÍAS Y PUEBLOS}

\section{III.A. Marco normativo Internacional}

III.A.1. Naciones Unidas: especial referencia al Pacto Internacional de Derechos Civiles y Políticos de 1966.

Naciones Unidas ha mostrado un esfuerzo constante y muy relevante en la promoción y desarrollo de la protección de los derechos de las minorías, a través de numerosos organismos y por medio de sus resoluciones. El Pacto Internacional de Derechos Civiles y Políticos de 1966 en su artículo 2.1 prohíbe la discriminación en el goce de los derechos en él reconocidos, y consagra en su artículo 26 la igualdad ante 
la ley, la igual protección de la ley, la prohibición de toda discriminación bajo la ley y la garantía de efectiva protección contra cualquier discriminación. Los dos artículos proclaman derechos reconocidos con carácter universal de manera que pueden también ser invocados por las minorías. Empero, no contienen una mera repetición del mismo derecho ${ }^{38}$. El artículo 2.1 consagra un principio general de no discriminación en los derechos del Pacto, de modo que complementan los artículos que establecen derechos sustantivos. El artículo 26, por su parte, consagra un derecho autónomo a la igualdad ante la ley y la igual protección de la ley sin discriminación, así como la garantía de la protección efectiva frente a cualquier discriminación de iure o de facto en cualquier ámbito regido por una autoridad estatal ${ }^{39}$.

El Pacto nombra expresamente a los "pueblos" (la Declaración Universal de los Derechos Humanos de 1948 no contenía alusión alguna a los grupos), incluyendo un reconocimiento al derecho a la libre determinación, en virtud del cual establecen libremente su condición política y proveen asimismo a su desarrollo económico, social y cultural (artículo 1.1). Para el logro de sus fines, todos los pueblos pueden disponer libremente de sus riquezas y recursos naturales, sin perjuicio de las obligaciones que derivan de la cooperación económica internacional basada en el principio del beneficio recíproco, así como del derecho internacional (artículo 1.2). Asimismo, se obliga a los Estados firmantes a promover el ejercicio del derecho de libre determinación, respetando este derecho de conformidad con las disposiciones de la Carta de las Naciones Unidas (art 1.3).

Por su parte, el artículo 27 recoge los tipos de minorías, reconociendo la existencia de minorías étnicas, religiosas o lingüísticas, de manera que "no se negará a las personas que pertenezcan a dichas minorías el derecho que les corresponde, en común con los demás miembros de su grupo, a tener su propia vida cultural, a profesar y practicar su propia religión y a emplear su propio idioma”. El uso de la expresión "personas que pertenezcan a dichas minorías" indica que se opta por la protección de los derechos individuales de los miembros del grupo, de manera que no puede interpretarse que alude al grupo considerado como tal ${ }^{40}$.

No obstante, conscientes del obstáculo que suponía la vaguedad terminológica adyacente al término, en 1971 la organización encargó a un Relator Especial un estudio en torno a la definición y clasificación de las minorías, el cual fue finalmente

38 MORAWA,A., "The United Nations treaty monitoring bodies and minority Rights with particular emphasis on the Human Rights Committee", Mechanisms for the Implementation of Minority Rights. Germany: Council of Europe Publishing, 2004, p. 39.

39 ARLETTAZ, F., "Derechos de las minorías en el Pacto Internacional de Derechos Civiles y Políticos": consideraciones conceptuales", en https://www.mruni.eu/upload/iblock/e0b/JUR-13-20-3-04.pdf

40 Algunos autores no comparten esta opinión. Ermacora afirma que el artículo 27 "puede ser interpretado también como un instrumento de protección del grupo", conteniendo "elementos de protección del grupo" (ERMACORA, F., "The Protección of Minorities before the United Nations", 182 Recueil des Cours (1983, IV), pág. 274. Para Distein, la finalidad que busca el artículo 27 es el reconocimiento de los derechos humanos colectivos de los miembros de una minoría, en concreto, de la minoría religiosa (DINSTEIN, Y., "Freedom of Religion and the Promotion of Religious Minorities", 20 IYHR, (1990), págs. 155-179). 
publicado en $1979^{41}$. El Relator Especial, después de analizar un amplio número de definiciones y tras someter a consideración de los gobiernos y de los miembros de la Sub-Comisión de Naciones Unidas para la Prevención de la Discriminación de las Minorías sus conclusiones, proporciona en su informe una definición: la minoría "es un grupo numéricamente inferior al resto de la población de un Estado, en situación no dominante, cuyos miembros, súbditos del Estado, poseen desde el punto de vista étnico, religioso o lingüístico, unas características que difieren de las del resto de la población; y manifiestan incluso de modo implícito, un sentimiento de solidaridad al objeto de conservar su cultura, sus tradiciones, su religión o su idioma" 42 .

El Informe Capotorti fue entregado a la Comisión de Derechos Humanos sin que esta Comisión llegara a estar de acuerdo con el contenido de la definición. La Sub-Comisión también había manifestado su disconformidad, por lo que en 1985 se encarga un nuevo trabajo de definición al canadiense Deschenes. Deschenes define finalmente el término como "un grupo de ciudadanos de un Estado, dotados de características étnicas, religiosas o lingüísticas diferentes a las de la mayoría de la población, solidarios los unos de los otros, animados, aunque sea implicitamente, de una voluntad colectiva de supervivencia y que tienden a la igualdad de hecho y de derecho con la mayoría" 43.

Posteriormente, la Declaración sobre los Derechos de las personas pertenecientes a minorías nacionales o étnicas, religiosas o lingüísticas, que fue aprobada el 18 de diciembre de 1992 (Resolución de la Asamblea General 47/135), desarrolló las previsiones contenidas en el Pacto de 1966, pero poniendo el énfasis en el reconocimiento de los derechos de las minorías no desde una perspectiva únicamente individual. En el artículo 1, establece la obligación de que los Estados protejan "la existencia y la identidad nacional o étnica, cultural, religiosa y lingüística de las minorías dentro de sus territorios respectivos" así como obliga al fomento de "las condiciones para la promoción de esa identidad. Para ello, los Estados deberán adoptar las medidas necesarias conducentes, entre otras, a garantizar que las personas pertenecientes a minorías puedan ejercer plena y eficazmente todos sus derechos humanos y libertades fundamentales sin discriminación alguna y en plena igualdad ante la ley (art.4.1 de la Declaración).

No obstante, la experiencia de las comunidades y grupos de todo el mundo muestran que persisten los principales motivos de preocupación, esto es, la supervivencia de estos grupos, la promoción y la protección de su identidad, la igualdad y la no discriminación, y la participación efectiva en la sociedad en sus diferentes ámbitos.

41 Es el conocido como Informe Capotorti.

42 Concepción elaborada en 1977 por Francesco Capotorti, relator especial de Naciones Unidas, en Estudio sobre los Derechos de las Personas Pertenecientes a Minorías Étnicas, Religiosas o Lingüísticas, citado en MARIÑO MENÉNDEZ, F., "La Protección Internacional de las Minorías", Ministerio de Trabajo y Asuntos Sociales, Madrid, 2001, pág. 16.

43 Propuesta Relativa a una Definición del Término Minoría, UN Doc. E/CN.4/Sub.2/1985/31, pár. 181, sometida por el relator especial de Naciones Unidas, Jules Deschenes, en 1985 a la Subcomisión de Prevención de las Discriminaciones y Protección de las Minorías. Citado en MARIÑO MENÉNDEZ, F., Op. cit., pág.16. 
En este contexto en el que hay que seguir avanzando, todas las contribuciones que se realicen son importantísimas pero deben partir de puntos clave como lograr una mayor implicación de los Estados en la efectividad de las medidas, para dar soluciones duraderas y resolutivas a la realidad de los grupos.

\section{III.A.2. Convenio Europeo de Derechos Humanos (Convenio de Roma).}

El Convenio Europeo de Derechos Humanos (Convenio de Roma, aprobado por el Consejo de Europa el 4 de noviembre de 1950) prohíbe expresamente la discriminación de las "minorías nacionales" ${ }^{44}$. El artículo 14 incluye una cláusula general en la que se nomina a las minorías nacionales como colectivo al que hay que asegurar de forma efectiva el goce de los derechos y libertades reconocidos en el Convenio.

Aun así, el precepto no ha bastado para garantizar efectivamente la igualdad de estos grupos en todos los casos y la erradicación general y definitiva de la discriminación ${ }^{45}$, de ahí que sigan aprobándose Documentos en este sentido. Al respecto, el Protocolo número 12 adoptado en Roma el 4 de Noviembre de 2000, en su primer artículo no solo ratifica la prohibición de cualquier discriminación contenido en artículo 14 del Convenio Europeo de Derechos Humanos, sino que extiende expresamente la prohibición a las actuaciones "por parte de cualquier autoridad pública, basada en particular en los motivos mencionados en el apartado 1", esto es, "por razones de sexo, raza, color, lengua, religión, opiniones políticas o de otro carácter, origen nacional o social, pertenencia a una minoría nacional, fortuna, nacimiento o cualquier otra situación”. El Protocolo 12 recoge la prohibición general de no discriminación como una cláusula independiente, de manera que, a partir de su aprobación, en las demandas ante el TEDH el petitum o causa petendi puede ser la propia discriminación.

Por su parte, el Tribunal Europeo de Derechos ha interpretado la igualdad reconocida en dicho art. 14, aclarando que "discriminar" significa "tratar de modo diferente, sin una justificación objetiva y razonable, a personas situadas en situaciones sustancialmente similares" (Willis contra Reino Unido, núm. 36042/97, apartado 48, TEDH 2002 IV; Okpisz contra Alemania, núm. 59140/00, apartado 33, 25 de octubre de 2005). Por lo tanto, el artículo 14 no prohíbe a un Estado miembro tratar grupos de manera diferente para corregir las “desigualdades fácticas” entre ellos. De hecho, la ausen-

\footnotetext{
44 Artículo 14: "El goce de los derechos y libertades reconocidos en el presente Convenio ha de ser asegurado sin distinción alguna, especialmente por razones de sexo, raza, color, lengua, religión, opiniones políticas $u$ otras, origen nacional o social, pertenencia a una minoría nacional, fortuna, nacimiento o cualquier otra situación".

45 Tavernier afirma que, si bien "presta elementos para la defensa de las personas pertenecientes a minorías nacionales, étnicas o lingüisticas", la realidad la ha revelado insuficiente (TAVERNIER, P., "A propos de la convention-cadre du Conseil de l'Europe pour la protection des minorités nationales”, RGDIP (Revue générale de droit international public), 1995, págs. 393-394). Esta opinión es compartida por Malinverni (MALINVERNI, G., "Le projet de convention pour la protection des minorities élaboré par la Commission eurpéenne pour la démocratie par le droit”, RUDH (Revue Universelle des Droits de l'bomme, 1991, pág. 160).
} 
cia de un trato diferencial cuyo objetivo es corregir una desigualdad puede considerarse, si no existe justificación objetiva y razonable, una violación de la disposición en cuestión (caso "sobre determinados aspectos del régimen de la lengua de la educación en Bélgica” contra Bélgica (fondo), 23 de julio de 1968, p. 34, apartado 10, serie A núm. 6; Thlimmenos contra Grecia GS, núm. 34369/97, apartado 44, TEDH 2000- IV; Stec y otros contra Reino Unido GS, núm. 65731/01, apartado 51, TEDH 2006 VI). El Tribunal también ha precisado que podría ser considerada discriminatoria una política o una medida general que tuviera efectos perjudiciales desproporcionados para un grupo de personas, aunque no tratara específicamente ese grupo (Hugh Jordan contra Reino Unido, núm. 24746/94, apartado 154, 4 de mayo de 2001; Hoogendijk contra Holanda (dec.), núm. 58641/00, 6 de enero de 2005).

La evolución del TEDH en la aplicación de las garantías del Convenio en materia de igualdad y erradicación de la discriminación es patente y meritoria, con un avance progresivo y consolidado a partir del caso "D. H. y otros contra la República Checa”, de 13 de noviembre de 2007, donde el Tribunal incorpora las categorías del Derecho Antidiscriminatorio procedentes del derecho anglosajón, que a su vez recibe el ordenamiento de la Unión Europea ${ }^{46}$. En su singular voto discrepante, el Juez español J. Borrego llega a comparar esta Sentencia con un "coche de Fórmula 1", que se distancia erróneamente a gran velocidad de la jurisprudencia anterior.

No obstante en materia de igualdad, la Carta Social Europea, la Carta Europea de Lenguas Regionales y el Convenio Marco para la Protección de las Minorías Nacionales, aprobados por el Consejo de Europa, serán los instrumentos que desarrollan más ampliamente el marco jurídico de los grupos minoritarios, por lo que pasaremos a verlos a continuación.

\section{III.A.3. Carta Social Europea}

La Carta Social Europea (CSE) constituye el instrumento más emblemático del Derecho europeo de los derechos sociales o, si se prefiere, del Derecho social de los derechos humanos ${ }^{47}$. El Consejo de Europa aprobó la Carta Social en $1961^{48}$ con la

46 REY MARTÍNEZ, F." La discriminación racial en la jurisprudencia del Tribunal Europeo de Derechos Humanos", Pensamiento Constitucional, $N^{\circ} 17,2012$. Esta sentencia constituye un leading-case, esto es, una Sentencia que establece la doctrina a aplicar en el futuro. La Gran Sala del Tribunal, con esta sentencia revocó la anterior de una Sala del mismo Tribunal, en virtud del art. 43 del Convenio Europeo de Derechos Humanos que permite, en "casos excepcionales" (en este caso se apreció importancia social, por parte de un colegio de cinco jueces) el "reexamen" de las Sentencias de Sala.

47 JIMENA QUESADA, L., "El Comité Europeo de Derechos Sociales: sinergias e impacto en el Sistema Internacional De Derechos Humanos y en los Ordenamientos Nacionales", Revista Europea de Derechos Fundamentales, Primer semestre 2015, 25, 99-127.

${ }^{48} \mathrm{La}$ Carta Social Europea fue abierta a la firma en Turín el 18 de octubre de 1961 y revisada en 1996 con el objetivo de actualizar su contenido. Esta revisión, que se abrió a la firma el 3 de mayo 1996, entró en vigor el 1 de julio de 1999. Además, el texto de la Carta Social de 1961 ha conocido diversas modificaciones que se arbitran a través de los Protocolos: el Protocolo adicional de 1988 que garantiza 
finalidad de constituir un complemento al Convenio Europeo de Derechos Humanos adoptado en 1950 para la protección de los derechos civiles y políticos, siendo su objetivo concreto, tal y como se detalla en el Preámbulo "el goce de los derechos sociales sin discriminación, la mejora del nivel de vida y la promoción del bienestar de los pueblos de los Estados contratantes, a través de instituciones y acciones apropiadas".

La Carta constituye un marco jurídico mínimo para la protección de los derechos sociales que todos los Estados miembros deben garantizar a sus ciudadanos y que se arbitra de la siguiente manera: las disposiciones de la Carta no afectarán a las disposiciones de Derecho interno ni de otros tratados vigentes y aplicables si estas últimas ofrecen un trato más favorable a las personas protegidas, tal y como recoge el artículo 32. Por el contrario, si el nivel de protección de la Carta es mayor, deberá aplicarse ésta. A esto hay que añadir la idoneidad de la Carta revisada como instrumento de coordinación de las políticas sociales europeas, tal y como ha reiterado el Consejo de Europa a través de sus distintas instancias, siendo lo deseable que adquiera una mayor influencia tanto en el orden constitucional de los Estados, como en el acervo comunitario de la UE. Efectivamente, la Carta, como paradigma de pacto europeo de los derechos sociales, y junto a la jurisprudencia que desarrolla el Comité Europeo de Derechos Sociales, son elementos indispensables cuyo impacto en el catálogo constitucional de derechos sociales y en el conjunto normativo vigente en la Unión Europea, debiera ser decisivo.

A pesar de esto, la realidad es que la indiscutible potencialidad de la Carta no termina de superar el muro de desconocimiento que de ella tienen tanto la opinión pública como los actores y políticos europeos ${ }^{49}$, lo que se traduce en una ausencia de efectividad que es lo que denuncia insistentemente el Consejo de Europa.

Por su parte, el Comité Europeo de Derechos Sociales (CEDS), compuesto por quince miembros independientes elegidos por el Comité de Ministros del Consejo de Europa por un mandato de seis años (renovable una sola vez), se configura como un órgano equiparable al TEDH en relación al CEDH, realizando funciones de control de la correcta aplicación de la Carta a través de un sistema de presentación de informes y un procedimiento de reclamaciones colectivas. El primero se desarrolla a partir de la elaboración de informes por parte de los Estados partes con carácter anual, en relación a una de las cuatro categorías de disposiciones temáticas de la Carta. De este

cuatro nuevos derechos; el Protocolo de enmienda de 1991 que prevé la reforma del mecanismo de control (y que formalmente no ha entrado en vigor al precisar la unanimidad de todos los Estados Partes en la Carta, pero cuyo contenido se aplica tras una decisión del Comité de Ministros de diciembre de 1991, mediante la que se pedía a los órganos de control de la Carta que, "en la medida en que el texto de la Carta lo permitiere”, aplicaran el Protocolo incluso antes de su entrada en vigor); y el Protocolo adicional de 1995 que establece el mecanismo de las reclamaciones colectivas.

49 JIMÉNEZ GARCÍA, F., "La Carta Social Europea (revisada): entre el desconocimiento y su revitalización como instrumento de coordinación de las políticas sociales europeas”, Revista electrónica de estudios internacionales, $\mathrm{n}^{\circ} 17,2009$. 
modo, cada Estado presentará informes sobre cada conjunto de disposiciones cada cuatro años $^{50}$, y en base a ellos, el CEDS expresa sus "conclusiones".

En cuanto al sistema de reclamaciones colectivas, éste legitima a las organizaciones de trabajadores (nacionales e internacionales) así como a otras organizaciones no gubernamentales, a presentar las reclamaciones de violación de los derechos humanos por parte de los Estados ante el Comité Europeo de Derechos Sociales, según el protocolo adicional de 1995, que entró en vigor en 1998, siempre y cuando el Estado haya reconocido este derecho. Al respecto, el CEDS emite "decisiones de fondo" con forma de sentencia.

De esta forma, los Estados Partes se obligan tanto por las disposiciones de la Carta Social Europea (la de 1961 y la revisada de 1996), como por la jurisprudencia emanada por el CEDS a través de los sistemas de informes y de reclamaciones colectivas. Ambos sistemas están vinculados, de manera que el CEDS se inspira y cita en sus "decisiones de fondo" la jurisprudencia elaborada en el sistema de informes y, a su vez, se inspira y cita en sus "conclusiones" la más reciente jurisprudencia desarrollada a través de la resolución de las reclamaciones colectivas ${ }^{51}$.

En relación con los grupos vulnerables, su protección ha motivado una incisiva actividad jurisprudencial, constituyendo las personas con discapacidad, la infancia, las personas extranjeras, las personas en situación socio-económica precaria, y algunas minorías (en particular, el colectivo gitano), el ámbito subjetivo de protección. En cuanto a éstas últimas, en 2010 se publicaron tres importantes decisiones de fondo en relación a dos reclamaciones colectivas: la Reclamación n 49/2008, la Reclamación $n^{\circ} 58 / 2009$ y la Reclamación nº 63/2010.

En la Reclamación no 49/2008 (INTERIGHTS contra Grecia, decisión de admisibilidad de 23 de septiembre de 2008), se denunció que el Gobierno griego desahuciara a la fuerza a las personas gitanas sin proponerles un alojamiento adecuado, a lo que se añadía que, en materia de acceso a la vivienda, los gitanos residentes en Grecia

so JIMENA QUESADA, L., "Crónica de la jurisprudencia del Comité Europeo de Derechos Sociales-2017”, Revista Europea de Derechos Fundamentales, Segundo Semestre 2017. Concretamente, las categorías son: Empleo, formación e igualdad de oportunidades: (artículos 1, 9, 10, 15, 18, 20, 24, 25); Salud, seguro social y protección social (artículos 3, 11, 12, 13, 14, 23, 30); Derechos laborales (artículos 2, 4, 5, 6, 21, 26, 28, 29); Niños, familias, migrantes (artículos 7, 8, 16, 17, 19, 27, 31). "Las conclusiones del CEDS (adoptadas en diciembre de 2017 y publicadas en enero de 2018) sobre los informes ordinarios (presentados cada año por los Estados Partes sobre uno de los cuatro bloques temáticos en los que se estructura la CSE a estos efectos) versaron sobre el grupo temático II, referente a "Salud, seguridad social y protección social", es decir, los arts. 3 (derecho a la salud y la seguridad en el trabajo), 11 (derecho a la salud), 12 (derecho a la seguridad social), 13 (derecho a la asistencia social y médica), 14 (derecho a los servicios sociales), 23 (derecho de las personas mayores a la protección social-art. 4 del Protocolo adicional de 1988-) y 30 (derecho a la protección contra la pobreza y la exclusión social). Los informes gubernamentales debian baberse presentado hasta el 31 de octubre de 2016 y cubrieron el período de referencia de 2012 a 2015 ".

51 JIMENA QUESADA, L., "Crónica de la jurisprudencia del Comité Europeo de Derechos Sociales-2010”, Revista Europea de Derechos Fundamentales, Segundo Semestre 2010, págs. 385-407.

N. ${ }^{\circ} 106$, septiembre-diciembre 2019, págs 199-250 
sufrían discriminación, todo ello invocando el artículo 16 de la Carta (protección social, jurídica y económica de la familia), autónomamente o en combinación con la cláusula de no discriminación del Preámbulo. Con la decisión de fondo de 11 de diciembre de 2009, el CEDS acogió la tesis impugnatoria de la entidad reclamante, declarando la vulneración del artículo 16 de la Carta Social. Para alcanzar esta conclusión, el CEDS se basa en los elementos probatorios proporcionados por INTERIGHTS, así como en otras fuentes concretas, como el informe de 2006 sobre la República Helénica del Comisario para los Derechos Humanos del Consejo de Europa, el informe anual correspondiente a 2008 de la Comisión nacional griega para los derechos humanos, el informe de 2009 sobre Grecia del experto independiente de Naciones Unidas sobre las cuestiones relativas a las minorías, el informe de 2009 sobre Grecia de la Comisión Europea contra el Racismo y la Xenofobia del Consejo de Europa, o el informe de octubre de 2009 de la Agencia de los Derechos Fundamentales de la Unión Europea sobre las condiciones de alojamiento de las personas de etnia gitana y gentes viajantes en la Unión Europea. De esta forma, el CEDS, pese a poner de relieve ciertos avances en la mejora de las condiciones de vida de las personas de etnia gitana (extensión del programa de préstamos inmobiliarios, tanto en número como en montante, o construcción de un nuevo campamento permanente y adopción de legislación antidiscriminatoria que se aplicaría al acceso a bienes y servicios, entre ellos, a la vivienda), considera ampliamente acreditado que un gran número de integrantes de la comunidad gitana continúan viviendo en campamentos que no responden a las normas mínimas exigibles.

Asimismo, el CEDS menciona tanto la jurisprudencia del TEDH ${ }^{52}$ (se citan, entre otras, las sentencias dictadas el 27 de mayo de 2004 o el 13 de mayo de 2008 en el caso Connors y en el caso McCann, respectivamente, ambos contra el Reino Unido) como la Observación General sobre la materia del Comité de Derechos Económicos, Sociales y Culturales de Naciones Unidas ( $\left.n^{\circ} 7\right)$, para considerar discriminatorios los desahucios forzosos padecidos por dichas personas en Grecia, basándose en argumentos como que un número considerable de personas de etnia gitana son desahuciadas forzosamente, en violación del artículo 16 de la Carta, sin ser consultadas previamente, sin un plazo razonable de preaviso y sin alternativa de realojamiento, a lo que hay que añadir que no son informadas sobre los recursos disponibles para contestar la orden de desahucio ${ }^{53}$.

52 Entre la jurisprudencia del TEDH y el CEDS se produce una necesaria sinergia que debe seguir desarrollándose y afianzándose: el CEDS utiliza la jurisprudencia del TEDH para argumentar sus decisiones, especialmente en el contexto del procedimiento judicial de reclamaciones colectivas. Por su parte, el TEDH ha ido aumentando progresivamente sus menciones a la jurisprudencia del CEDS. Para más información se recomienda leer el artículo de Jimena Quesada "El Comité Europeo De Derechos Sociales: sinergias e impacto en el Sistema Internacional De Derechos Humanos y en los Ordenamientos Nacionales", en Revista Europea de Derechos Fundamentales, primer semestre 2015, págs. 99-127.

53 JIMENA QUESADA, L., "Crónica de la jurisprudencia del Comité Europeo de Derechos Sociales-2010”, Revista Europea de Derechos Fundamentales, Segundo Semestre 2010, págs. 385-407. 
Por su parte, la decisión de fondo de 25 de junio de 2010 sobre la Reclamación $n^{\circ} 58 / 2009$ (Centre on Housing Rights and Evictions contra Italia), estimó las pretensiones de la organización reclamante que reprochaban a las autoridades italianas la legislación de emergencia adoptada para hacer frente a la situación de las personas gitanas (población romaní y sinti) por exponerlas a un discurso racista y xenófobo, así como someterlas a expulsiones ilegales tanto de los campamentos como del territorio italiano, con vulneración de los artículos 16 (protección social, jurídica y económica de la familia), 19 (protección y asistencia de los trabajadores migrantes y sus familias), 30 (protección contra la pobreza y la exclusión social) y 31 (derecho a la vivienda), invocados autónomamente y en conexión con la cláusula de no discriminación del artículo E de la Carta revisada. Esta decisión conllevó la peculiaridad de que, en la decisión de admisibilidad de 8 de diciembre de 2009, el CEDS acordó por primera vez utilizar el procedimiento preferente y sumario previsto en el artículo 26 del Reglamento, a la vista de la gravedad de las violaciones denunciadas en la reclamación colectiva.

La decisión de fondo de 25 de junio de 2010 sobre la Reclamación no 58/2009 está constituida por cuatro partes: en la primera se declara la violación del art. E (no discriminación) en combinación con el art. 31 (derecho a la vivienda), por la situación de exclusión social y condiciones deplorables sufridas por las personas de etnia gitana, ubicadas en guetos en la periferia de las ciudades (apartado 1); por la estigmatización de esas personas provocada por las "medidas de seguridad" (conocidas como "emergenza rom”) adoptadas por las autoridades italianas, que no solo habrían permitido la perpetración de violencia generalizada por individuos y grupos organizados contra campamentos y asentamientos gitanos, sino que habrían contribuido a favorecer dicha violencia por medio de reprochables intervenciones y omisiones policiales (apartado 2); y por la falta de acreditación por parte de las autoridades italianas de la adopción de medidas, sin perjuicio del nivel territorial competente en la materia, tendentes a facilitar el acceso a viviendas sociales sin discriminación (apartado 3)107.

En la segunda parte de la decisión de fondo de 25 de junio de 2010 se estima la violación del art. E en conjunción con el art. 30 (derecho a protección contra la pobreza y la exclusión social), tanto por las condiciones de pobreza derivadas de la segregación y marginación engendradas en los campamentos gitanos, como por la exclusión social de las personas de etnia gitana de toda posible participación ciudadana y política, a lo que habrían contribuido los poderes públicos italianos al poner obstáculos al respeto de la identidad étnica y las opciones culturales de esa minoría en la cultura, los medios de comunicación y los diferentes niveles administrativos, y al no facilitar la obtención de los documentos de identidad que permiten acceder a la condición de elector.

En la tercera parte se constata la violación del art. E en relación con el art. 16 (protección de la familia), tanto en la vertiente clásica de protección social y acceso a la vivienda como en una faceta novedosa que constituye una jurisprudencia nueva del CEDS, elaborada por analogía con respecto a la jurisprudencia del TEDH sobre el art. 
$8 \mathrm{CEDH}$ ) relativa a la protección frente a las injerencias injustificadas y discriminatorias en la vida familiar de las personas de etnia gitana, por el modo en que se ha producido el censo e identificación de dichas personas en los campamentos (huellas digitales, almacenamiento de datos fotométricos e incluso en algunos casos una etiqueta identificativa para acceder al campamento), lo cual no habría comportado un respeto de las normas internacionales en la materia (principios de declaración individual voluntaria y de autoidentificación; cooperación con los órganos de supervisión nacionales e internacionales, y consulta con las ONGs que representan o trabajan con esos colectivos vulnerables; confidencialidad, "habeas data" y compilación de respuestas múltiples relativas a la pertenencia étnica por parte de personal cualificado).

Finalmente, en la cuarta parte se reconoce la violación del art. E combinado con el art. 19 de la Carta Social (derecho de los trabajadores migrantes y sus familias a protección y asistencia), por la flexibilización de la legislación antidiscriminatoria sobre incitación al odio racial y la violencia, así como por la propaganda racista engañosa contraria a los inmigrantes romanís y sintis tolerada o emanada directamente de las autoridades públicas (apartado 1; se constata por el CEDS una violación agravada); por la discriminación contra esa población inmigrante gitana en situación regular en el acceso al alojamiento subvencionado y ayudas sociales [apartado 4.c)]; y por haber utilizado las "medidas de seguridad" como dispositivo normativo discriminatorio tendente a expulsar colectivamente a personas de etnia gitana (se cita en apoyo la STEDH Conka c. Bélgica, de 5 de febrero de 2002), incluso a muchas de ellas que reunían las condiciones para ostentar la nacionalidad italiana pese a no poder demostrarlo por las trabas administrativas en el acceso a la documentación de identidad.

Asimismo, el CEDS aprecia que no solo las autoridades italianas habrían incumplido la decisión de fondo adoptada al respecto el 7 de diciembre de 2005 con motivo de la Reclamación no 27/2004 sino que, además, al aplicar medidas regresivas, habrían agravado la situación apreciada con anterioridad, conculcando de lleno el principio de que la realización de los derechos sociales fundamentales reconocidos por la Carta Social está guiada por la progresividad. Asimismo el CEDS señala además que, aunque el grupo vulnerable que es objeto de la reclamación comprenda no sólo personas de nacionalidad italiana y otros nacionales con residencia legal en territorio italiano, sino que a éstos hay que añadir personas en situación irregular que no responderían a la definición del ámbito personal de aplicación previsto en el Anexo a la Carta, la ausencia de posibilidades de identificación de este segundo colectivo no pueden constituir una privación de los derechos a la vida y a la dignidad, para lo que el CEDS cita dos decisiones de fondo previas, adoptadas el 8 de septiembre de 2004 con motivo de la Reclamación $n^{\circ} 14 / 2003$, Federación Internacional de Ligas de Derechos Humanos contra Francia, y el 20 de octubre de 2009 con ocasión de la Reclamación no 47/2008, Defence for Children International contra Países Bajos.

El CEDS cita su propia jurisprudencia y la del TEDH para recordar que el artículo E prohíbe no sólo la discriminación directa sino asimismo todas las formas de discriminación indirecta (decisiones de fondo adoptadas el 4 de noviembre de 2003 
sobre la Reclamación no 13/2002, Autismo- Europa contra Francia, y el 18 de octubre de 2006 sobre la Reclamación no 31/2005, Centro de Derechos para los Gitanos Europeos contra Bulgaria), que la carga de la prueba en asuntos de discriminación sobre personas vulnerables debe prever una inversión o desplazamiento apropiados (decisión de fondo de 3 de junio de 2008 sobre la Reclamación no 41/2007, Centro de defensa de los derechos de las personas con discapacidades mentales contra Bulgaria). Asimismo, puntualiza que la discriminación basada en el origen étnico constituye una forma de discriminación racial que no tiene cabida en una sociedad democrática contemporánea fundada en los principios de pluralismo y diversidad cultural (STEDH Timichev contra Rusia, de 13 de diciembre de 2005), y que las personas de etnia gitana constituyen un minoría desfavorecida y vulnerable necesitada de protección especial (STEDH Orsus contra Croacia, de 16 de marzo de 2010).

En la decisión de fondo de 28 de junio de 2011 sobre la Reclamación n 63/2010 (Centre on Housing Rights and Evictions contra Francia), el CEDS adopta por unanimidad una solución condenatoria por el desalojo y desmantelamiento de campamentos gitanos, así como las expulsiones de Francia de las personas de etnia gitana (básicamente de nacionalidad búlgara y rumana) durante el verano de 2010, rechazando así la argumentación del Gobierno francés según la cual las expulsiones de personas gitanas procedentes de Bulgaria y Rumanía no habrían sido colectivas. El CEDS concluyó que se produjo una violación del art. E (no discriminación) combinada con el art. 31.2 (que obliga a prevenir y paliar la situación de carencia de hogar con vistas a eliminar progresivamente dicha situación) y con el art. 19.8 CSE revisada de 1996 (que recoge las garantías relativas a la expulsión de los trabajadores migrantes y sus familias), apreciándose además que había mediado una responsabilidad y violación agravadas (apartado 53$)^{54}$.

Es necesario mencionar que una de las funciones primordiales del CEDS debe ser comprobar en los siguientes informes estatales que sigan al procedimiento de reclamaciones colectivas o al sistema de informes, que el Estado en cuestión haya dado cumplimiento a las observaciones efectuadas por el CEDS en sus conclusiones y/o haya reparado la situación que vulneraba la CSE. Al respecto, se puede citar como ejemplo de cumplimiento que han llevado a cabo los Estados partes, la reforma legislativa que tuvo su origen en la Reclamación n 48/2008 (Centro Europeo de Derechos de los Gitanos contra Bulgaria) por la que se eliminó un artículo de la ley de asistencia social que limitaba el acceso a dicha prestación a los parados, tras 6, 12 o 18 meses, lo que

${ }^{5}$ JIMENA QUESADA, L., "El Comité Europeo De Derechos Sociales: sinergias e impacto en el Sistema Internacional De Derechos Humanos y en los Ordenamientos Nacionales”, en Revista Europea de Derechos Fundamentales, primer semestre 2015, págs. 118-119; JIMENA QUESADA, L., "Protection of Refugees and other Vulnerable Persons under the European Social Charter", Revista de Derecho Político, n ${ }^{\circ} 92$, enero-abril 2015, págs. 245-272. Esta decisión, además de tener un gran impacto mediático, llegó a provocar la intención de la Comisión Europea de iniciar formalmente un procedimiento de infracción contra Francia ante el Tribunal de Justicia de la Unión. No obstante, después de las oportunas negociaciones políticas esta iniciativa no vio la luz. 
violaba lo dispuesto en el art. 13.1 de la CSE. De acuerdo con la resolución CM/ ResChS (2010)2, el Comité de Ministros estimó que dicha reforma legislativa se hallaba en plena concordancia con la decisión de fondo emitida por el CEDS y que suponía una solución eficaz y permanente.

Asimismo, el CEDS se está afianzando como la instancia europea de protección de derechos sociales, realizando su actividad de forma autónoma pero sin dejar de mantener una conexión con los desarrollos recientes en materia de derechos sociales realizados por otros órganos internacionales. De esta forma, se nutre de las instancias internacionales mencionadas en su jurisprudencia, y a la vez puede resultar útil a otros mecanismos de nueva instauración, como el nuevo procedimiento de comunicaciones individuales establecido mediante el Protocolo facultativo al Pacto internacional de derechos económicos, sociales y culturales, adoptado el 18 de junio de 2008 por el Consejo de Derechos Humanos de Naciones Unidas. Todo ello sin olvidar las sinergias entre el TEDH y el CEDS, en el seno del Consejo de Europa. Con respecto a la Unión Europea, y sin dejar de lado la posibilidad de una adhesión a la Carta Social Europea, debe advertirse que la jurisprudencia del CEDS, por más que no se mencione explícitamente en la Carta de los derechos fundamentales de la Unión, habrá de tenerse en cuenta con prioridad a las Explicaciones del Praesidium (el órgano redactor de dicha Carta de la Unión), desde el momento en que la jurisprudencia del CEDS es más acertada cuando se trata de interpretar los derechos consignados en la Carta de la Unión cuya redacción se ha basado expresamente en la Carta Social Europea ${ }^{55}$.

Por último, no podemos dejar de aludir a la situación actual en España. España ratificó la Carta el 6 de mayo de 1980, entrando en vigor el 5 de junio de ese mismo año. Posteriormente, la Carta revisada fue firmada el 23 de octubre de 2000, sin embargo se ha ido posponiendo su ratificación ante la necesidad de adaptar algunos aspectos de la legislación española. No obstante, el 1 de febrero de 2019, el Consejo de Ministros ha aprobado un Acuerdo por el que se ha autoriza su remisión a las Cortes Generales para proceder a su ratificación ${ }^{56}$. Nada se dice, sin embargo, sobre el Protocolo de reclamaciones colectivas de 1995, que constituye un mecanismo de garantía fundamental de la Carta, cuya ratificación aún no se ha producido. Semejante tarea pendiente resulta como mínimo desconcertante, en tanto en cuanto España ratificó el 23 de septiembre de 2010 el Protocolo facultativo al Pacto de Derechos Económicos, Sociales y Culturales de la $\mathrm{ONU}^{57}$, que establece un mecanismo de comunicaciones o denuncias individuales similar al instaurado a través de otros instrumentos de Naciones Unidas (Protocolos Facultativos al Pacto de Derechos Civiles y Políticos o a la Convención sobre los derechos de las personas con discapacidad, o el artículo 14 de la Convención sobre la eliminación de todas las formas de discrimi-

55 JIMENA QUESADA, L., "La protección de los grupos vulnerables por el Consejo de Europa", en el libro "Colectivos vulnerables y derechos humanos. Perspectiva internacional", Ed. S. Sanz Caballero, Valencia, Tirant lo Blanch, 2010, págs. 15-42.

56 http://www.lamoncloa.gob.es/consejodeministros/Paginas/enlaces/010219-enlacecartasocial.aspx

57 Adoptado por la Asamblea General, el 10 de diciembre de 2008. 
nación racial). Lo que no es posible obviar es que, aun cuando se culmine el procedimiento de ratificación de la Carta revisada, al no acometer en paralelo la ratificación del Protocolo de reclamaciones colectivas de 1995, España va a seguir sufriendo un déficit social que la aleja de manera inexcusable de la protección en derechos sociales que se consagra en el seno del Consejo de Europa e, inclusive, de la Unión Europea. Si a ello añadimos las consecuencias en el plano social de la reciente y complicada crisis económica que aun no puede presumirse superada en su totalidad y que ha supuesto una grave merma en el contenido y garantías del Estado social que consagra nuestra Constitución, la posición española se revela insuficiente.

\section{III.A.4. Carta Europea de Lenguas Regionales o Minoritarias.}

La Carta Europea de Lenguas Regionales o Minoritarias se aprueba en 1992, entrando en vigor en 1998. Su finalidad, tal y como se detalla en el Preámbulo, es proteger "las lenguas regionales o minoritarias históricas de Europa, de las que algunas corren el riesgo de desaparecer con el tiempo", puesto que contribuyen "al mantenimiento y al desarrollo de las tradiciones y la riqueza culturales de Europa". Asimismo, proclama que el derecho a utilizar una lengua regional o minoritaria en la vida privada y publica constituye "un derecho imprescriptible, de conformidad con los principios contenidos en el Pacto Internacional de Derechos Civiles y Políticos de las Naciones Unidas, y de acuerdo con el espiritu del Convenio del Consejo de Europa para la Protección de los Derechos Humanos y de las Libertades Fundamentales". De esta forma, el ejercicio de los derechos que reconoce los vincula a la protección de los derechos humanos expresamente. Para mayor claridad, el artículo 4 obliga a que ninguna de las disposiciones se pueda interpretar en el sentido de que limite o derogue los derechos garantizados por el Convenio Europeo de Derechos Humanos, ni de manera que afecten a las disposiciones más favorables que rijan en materia de las lenguas regionales o minoritarias. Tampoco al régimen jurídico de las personas que pertenecen a minorías que existan ya en una Parte o que estén previstas por acuerdos internacionales bilaterales o multilaterales pertinentes. A esto hay que añadir una precisión: la protección y el fomento de las lenguas regionales o minoritarias no deben hacerse en detrimento de las lenguas oficiales y de la necesidad de aprenderlas.

La Carta también se ocupa de definir lo que se entiende por "lenguas regionales o minoritarias" y por "territorio en que se habla una lengua regional o minoritaria" (artículo 1). Por la primera expresión se alude a aquellas lenguas habladas tradicionalmente en un territorio de un Estado por nacionales de ese Estado que constituyen un grupo numéricamente inferior al resto de la población, y aquellas diferentes de la(s) lengua(s) oficial(es) del Estado, excluyendo explícitamente los dialectos de la(s) lengua(s) oficial(es) del Estado y las lenguas de los inmigrantes. Por "territorio en que se habla una lengua regional o minoritaria" se entenderá el área geográfica en la cual dicha lengua es el modo de expresión de un número de personas que justifica la adopción de las dife- 
rentes medidas de protección y fomento previstas en la presente Carta. Respecto a la definición de las "lenguas sin territorio", éstas se refieren a las lenguas habladas por nacionales del Estado que son diferentes de la(s) lengua(s) empleada(s) por el resto de la población del Estado, pero que, a pesar de emplearse tradicionalmente en el territorio del Estado, no se pueden circunscribir a un área geográfica concreta del mismo.

Además, los Estados firmantes se comprometen a que su política y su legislación se basen en objetivos y principios que son ampliamente recogidos en el art. 7.1, y entre los que se encuentran el fomento de las lenguas regionales o minoritarias; el mantenimiento y el desarrollo de relaciones, en los ámbitos de los que se ocupa la Carta, entre los grupos que empleen una lengua regional o minoritaria y otros grupos del mismo Estado que hablen una lengua utilizada de manera idéntica o parecida; o el fomento del empleo oral y escrito de las lenguas regionales o minoritarias en la vida pública y en la vida privada.

En la última parte del texto (Parte IV) se instaura un procedimiento a través del cual se pretende determinar su grado de aplicación y garantizar así la eficacia de sus normas. Las partes deben presentar periódicamente al Secretario general del Consejo de Europa un informe concerniente a las políticas seguidas y las medidas adoptadas, informe que deberá hacerse público (art. 15).

En definitiva, la Carta pone en valor la importancia de las lenguas, reconociendo expresamente que las lenguas regionales o minoritarias contribuyen a mantener y desarrollar la riqueza cultural de Europa como factor crucial en la construcción de las identidades colectivas. Actualmente, es posible afirmar que el balance que ofrece la Carta en cuanto a consecución de objetivos es meritorio, aunque precisa de una tarea de reinterpretación de su articulado con la finalidad de actualizar los contenidos, así como el perfeccionamiento del sistema de control de su cumplimiento por parte de los Estados. No obstante, constituye el principal instrumento jurídico de protección de las lenguas europeas no oficiales ${ }^{58}$.

\section{III.A.5. Convenio Marco para la Protección de las Minorías Nacionales.}

En el marco del Consejo de Europa, el Committee on Legal Affairs and Human Rights, elaboró una propuesta de definición de "minoría nacional" que englobaba a grupos separados o distintos, bien definidos y establecidos desde hace tiempo en el territorio de un Estado ${ }^{59}$. Posteriormente, la Comisión Europea para la Democracia a través del Derecho (conocida como Comisión Venecia) presenta una Propuesta de Convención Europea para la Protección de las Minorías, elaborada el 8 de febrero de

58 Para más información consultar RUIZ VIEYTEZ, E., "La Carta Europea de las Lenguas Regionales o Minoritarias en su veinte aniversario: balance y retos de futuro", Revista de Llengua i Dret, Journal of Language and Law, $\mathrm{n}^{\circ}$. 69, 2018, págs. 18-27

59 Parliamentary Assembly of The Council Of Europe, "Report on the rights of national minorities", Doc. 1299, 26 abril 1961, p. 7. 
1991, cuyo artículo 2 señala que “(...) el término minoría designa un grupo numéricamente inferior al resto de la población de un Estado, cuyos miembros, que tienen la nacionalidad de ese Estado, poseen características étnicas, religiosas o lingüísticas diferentes de las del resto de la población y están animadas por una voluntad de preservar su cultura, sus tradiciones, su religión o su lengua". Con esta definición se incorporan aspectos novedosos en la conceptualización de la minoría como la "inferioridad numérica del grupo" ante el resto de la población del Estado donde se localiza y la presencia de rasgos característicos comunes (lengua, religión, usos, costumbres, etc.). Asimismo, se incluye en la definición el elemento subjetivo consistente en la "voluntad del grupo de mantener esas características propias" y la incorporación del elemento de la nacionalidad. Esta Propuesta inspiraría el Convenio Marco para la Protección de las Minorías Nacionales cuyo texto, sin embargo, no recoge ninguna definición de minoría nacional.

Más adelante, la Asamblea Parlamentaria del Consejo de Europa consigue incluir una definición en la Recomendación 1201 de 1993 relativa a la propuesta de un Protocolo adicional al Convenio Europeo de los Derechos Humanos y de las Libertades Fundamentales referido a las personas pertenecientes a las minorías nacionales. Esta definición es la que se plasmó en la resolución 1255 de 31 de enero de 1995 , definiendo a la minoría nacional como un grupo de personas que: a) residen en el territorio de un Estado del que son sus ciudadanos; b) mantienen antiguos lazos sólidos y permanentes con este Estado; c) presentan características étnicas, culturales, religiosas o lingüísticas específicas; d) son suficientemente representativas a pesar de ser menos numerosas que el resto de la población del Estado o de una región del Estado; y e) están animadas por la voluntad de preservar conjuntamente su identidad común, principalmente su cultura, tradiciones, religión o lengua.

En relación con las anteriores definiciones esta última incorporó novedades, como el hecho de que el grupo minoritario mantenga con el Estado donde reside vínculos antiguos, sólidos y permanentes o la necesidad de que las minorías sean suficientemente representativas. Sin embargo, este nuevo criterio presenta problemas de cara a establecer cuándo una minoría puede considerarse suficientemente representativa, lo que provoca una gran inseguridad jurídica.

Por su parte, el Convenio Marco para la Protección de las Minorías Nacionales, adoptado en Estrasburgo el 1 de febrero de 1995, al introducir la expresión "...y los demás Estados...”, incorpora la pretensión de no ceñirse únicamente al ámbito restringido del Consejo de Europa ${ }^{60}$. Seguidamente, en el artículo 1, encuadra jurídicamente la protección de los derechos y libertades de los miembros de las minorías como

${ }^{60}$ Preámbulo: "Los Estados Miembros del Consejo de Europa y los demás Estados...". 
parte integrante de la protección internacional de los derechos humanos ${ }^{61}$, y en cuanto a tal, dentro del campo de la cooperación internacional ${ }^{62}$.

Sin embargo, el Convenio tampoco nos proporciona una definición del concepto de "minorías nacionales", soslayando la complejidad de encontrar un significado que satisfaga a todos los Estados parte. El artículo 5 nos da algunas "pistas" de lo que se considera como tal, claramente influenciado por el Pacto Internacional de Derechos Civiles y Políticos de 1966: son aquellos grupos de personas con una serie de elementos diferenciadores e identitarios respecto a la estructura mayor, a saber, su religión, lengua, tradiciones y/o patrimonio cultural ${ }^{63}$. Pero la enumeración, desde luego, no abarca todas las posibilidades reales en la tipología de las minorías, puesto que " $n i$ todas las minorías étnicas, religiosas y lingüísticas son minorías nacionales, ni ésta se reduce a ellas" ${ }^{4}$.

El artículo 3 traslada hacia los miembros de la minoría la potestad de elegir libremente ser o no considerado como tal, garantizando que el ejercicio de esa opción y de los derechos relacionados con la misma no dará lugar a ninguna desventaja. Es el ser individual, libre y consciente de su identidad personal y cultural, por tanto, el que elige si se identifica a sí mismo como miembro de una minoría nacional y, por lo tanto, se le aplica el Convenio.

En otro orden, el Convenio Marco no reconoce derechos individuales o colectivos a sus miembros (con la excepción del artículo 3). El texto contiene disposiciones de carácter programático que marcan los objetivos que los Estados han de alcanzar. De esta manera se hace indispensable acometer un desarrollo normativo posterior, para el que los Estados disponen de un amplio margen en el cual pueden determinar las normas de Derecho interno necesarias para lograr el resultado perseguido. Entre estos objetivos se encuentran el desarrollo de una igualdad completa y efectiva; la tolerancia y el dialogo intercultural, la libertad de asociación, el derecho a las propias creencias religiosas y de culto, el uso de lenguas minoritarias, aprendizaje de y en lenguas minoritarias; y la participación efectiva en asuntos públicos.

${ }^{61}$ Artículo 1: "La proteción de las minorías nacionales y de los derechos y libertades de las personas pertenecientes a esas minorías es parte integrante de la protección internacional de los derechos humanos y, en cuanto tal, se encuentra dentro del campo de la cooperación internacional".

${ }^{62}$ En el Explanatory Memorandum se puntualiza que el objetivo del precepto es señalar que la protección de los derechos de las minorías nacionales es una cuestión de carácter internacional y no una problemática exclusiva de los Estados.

63 Art. 5: "Las Partes se comprometen a promover las condiciones necesarias para permitir a las personas pertenecientes a minorías nacionales mantener y desarrollar su cultura, así como preservar los elementos esenciales de su identidad, a saber, su religión, lengua, tradiciones y patrimonio cultural".

${ }^{64}$ SUÁREZ PERTIERRA, G., SOUTO GALVÁN, E., CIÁURRIZ LABIANO, M.J., "Derecho y minorías", UNED, Madrid, 2014, pág. 87. 
El texto, además de consagrar el principio de igualdad y no discriminación de los miembros de las minorías, también recoge la posibilidad de que los Estados apliquen medidas de acción positiva encaminadas a lograr la igualdad plena y efectiva ${ }^{65}$.

En definitiva, después de analizar los instrumentos jurídicos más relevantes en el seno del Consejo de Europa, podemos concluir tanto que la protección de los derechos de las minorías se sitúan en el ámbito de protección de los derechos humanos, como que en la protección jurídica a las minorías no cabe considerarse reconocido un derecho de autodeterminación de los pueblos, entendido como el establecimiento o creación de un nuevo Estado soberano e independiente al territorio del Estado parte del Consejo de Europa, donde habiten las minorías. De forma expresa, el Preámbulo del Convenio Marco para la Protección de las Minorías Nacionales especifica las limitaciones fundamentales que la protección efectiva de las minorías nacionales y de los derechos y libertades de las personas pertenecientes a las mismas deben respetar: la preeminencia del Derecho, la integridad territorial y la soberanía. Asimismo, el artículo 21 establece que ninguna de sus disposiciones podrá interpretarse en el sentido de que implique el derecho a realizar cualquier acto contrario a los principios fundamentales del derecho internacional y, en particular, de la igualdad soberana territorial e independencia política de los Estados. Ahora bien, se concede la potestad de disfrutar de un cierto grado de autonomía dentro del Estado. Esta es la interpretación que cabe tras la lectura de los artículos 8, 9, 10 ó 17 del Convenio Marco.

Aun así, la doctrina admite la posibilidad de que las minorías dispongan del derecho a ejercer la autodeterminación en su manifestación de crear un Estado independiente, o integrarse en otro Estado soberano, en el caso de que el Estado donde el grupo habita no respete los derechos humanos básicos de sus miembros o atente contra principios fundamentales del derecho internacional ${ }^{66}$.

\section{III.A.6. La Unión Europea.}

La protección de las minorías nacionales es uno de los principios fundacionales de la Unión Europea. El artículo 2 del Tratado de la Unión Europea menciona expresamente a las minorías para incluir y remarcar la protección y respeto de sus derechos en el contexto general axiológico, político y social que constituye el fundamento y la

${ }^{65}$ Artículo 4.1.: Las Partes se comprometen a garantizar a las personas pertenecientes a minorías nacionales el derecho a la igualdad ante la ley y a una protección igual por parte de la ley. A este respecto, se probibirá toda discriminación fundada sobre la pertenencia a una minoría nacional. 2. Las partes se comprometen a adoptar, cuando sea necesario, medidas adecuadas con el fin de promover, en todos los campos de la vida económica, social, política y cultural, una plena y efectiva igualdad entre las personas pertenecientes a una minoría nacional y las pertenecientes a la mayoría. A este respecto, tendrán debidamente en cuenta las condiciones específicas de las personas pertenecientes a las minorías nacionales. 3. Las medidas adoptadas de conformidad con el apartado 2 no se considerarán un acto de discriminación.

${ }^{66}$ DÍAZ BARRADO, C.M., "La Protección de las minorías Nacionales por el Consejo de Europa", Editorial Edisofer, Madrid, 1999, pág. 58. 
base de la Unión: "La Unión se fundamenta en los valores de respeto de la dignidad humana, libertad, democracia, igualdad, Estado de Derecho y respeto de los derechos bumanos, incluidos los derechos de las personas pertenecientes a minorías. Estos valores son comunes a los Estados miembros en una sociedad caracterizada por el pluralismo, la no discriminación, la tolerancia, la justicia, la solidaridad y la igualdad entre mujeres y hombres". El incumplimiento de los valores consagrados en el art.2 por parte de los Estados miembros de la UE puede llevar a activar los mecanismos previstos en el art. 7 TUE y puede, entre otras cosas, conducir a la suspensión de ese estado de la Unión.

No obstante, el art. 2 no proporciona una definición de "minoría” o "derechos de las minorías". De esta forma, la Unión Europea sigue la estela marcada por el derecho internacional, sin que la legislación de desarrollo de la UE se haya ocupado de suplir la carencia, lo que puede traducirse, de facto, en que la aplicación del art.2 pueda evitarse a voluntad por parte de los Estados miembros. Sin embargo, y aunque se argumente que los términos indefinidos poseen la ventaja de la flexibilidad y, por lo tanto, pueden aplicarse a grupos y derechos sin romper los límites delimitados formalmente ${ }^{67}$, la práctica en el ámbito que nos ocupa nos revela que esta indeterminación actúa en detrimento de la protección efectiva de las minorías.

El artículo 3 establece que la Unión "respetará la riqueza de su diversidad cultural y lingüística y velará por la conservación y el desarrollo del patrimonio cultural europeo", así como contribuirá y fomentará la protección de sus ciudadanos y el "respeto mutuo entre los pueblos". La disposición encuentra apoyo tanto en el artículo 55 (2) del TUE, que estipula que el Tratado de la UE se traducirá a las lenguas que gozan de estatus oficial en todos o partes de los territorios de los Estados miembros, como en la Declaración 16 del Tratado de Lisboa, que confirma el propósito de art.55 (2) como contribución al cumplimiento de la diversidad defendida en art.3.

Asimismo, en la consolidación de un marco normativo de las minorías a nivel europeo, debemos resaltar la promulgación de dos Directivas: la Directiva 2000/43/ CE, de 29 de junio de 2000, relativa a la aplicación del principio de igualdad de trato de las personas independientemente de su origen racial o étnico, y la Directiva 2000/78/CE, de 27 de noviembre de 2000, relativa al establecimiento de un marco general para la igualdad de trato en el empleo y la ocupación. La primera Directiva, busca "garantizar el desarrollo de sociedades democráticas y tolerantes en las que toda persona pueda participar, con independencia de su origen racial o étnico”, prohibiendo la "discriminación, directa o indirecta, por motivos de origen racial o étnico" en ámbitos como "la educación, la protección social, incluida la seguridad social y la asistencia sanitaria, las ventajas sociales, la oferta de bienes y servicios y el acceso a los mismos" (considerandos 12 y 13 ).

La segunda Directiva busca el establecimiento de este marco general de igualdad y no discriminación en el empleo y la formación profesional. Artículo 1: "La presente

${ }^{67}$ AHMED, T., "The Treaty of Lisbon and Beyond: The Evolution of EU Minority Protection?", European Law Review, Vol. 38, n¹, 2013, págs. 30-51. 
Directiva tiene por objeto establecer un marco general para luchar contra la discriminación por motivos de religión o convicciones, de discapacidad, de edad o de orientación sexual en el ámbito del empleo y la ocupación, con el fin de que en los Estados miembros se aplique el principio de igualdad de trato".

No obstante, en 2005 el Parlamento de la Unión Europea ${ }^{68}$ puso de manifiesto nuevamente, la necesidad de que se adoptara un estándar de derechos de las minorías en el ámbito de la Unión, así como la confusión existente respecto al significado concreto de la expresión "un miembro de una minoría”. El Parlamento consideró como una solución posible adoptar la definición recogida en la Resolución 1201 de $1993^{69}$ del Consejo de Europa, según la cual una "minoría nacional” es un grupo de personas en un Estado que:

- reside en el territorio de ese Estado,

- mantiene desde antiguo lazos firmes y duraderos con ese Estado,

- ostenta características distintivas de carácter étnico, cultural, religioso o lingüístico,

- es suficientemente representativo a pesar de estar formado por un número reducido en relación con el resto de la población del Estado o de una región del mismo,

- está motivado por el interés de preservar conjuntamente aquello que constituye su identidad común, incluida su cultura, sus tradiciones, su religión o su idioma;

El Parlamento reconoce la imposibilidad de alcanzar una solución única para mejorar la situación de todas las minorías en todos los Estados miembros, por lo que aboga por el desarrollo de unos objetivos mínimos comunes para las autoridades públicas de la UE, basados en la experiencia, "en particular en las mejores prácticas y el diálogo social emprendido en muchos Estados miembros y en la aplicación del Pacto Internacional de Derechos Civiles y Políticos de las Naciones Unidas, de la Convención Internacional sobre la Eliminación de todas las Formas de Discriminación Racial de las Naciones Unidas y de los Convenios del Consejo de Europa tales como el Convenio marco sobre la Protección de las Minorías Nacionales y la Carta Europea de las Lenguas Regionales o Minoritarias y el Protocolo $n^{\circ} 12$ del Convenio europeo de derechos humanos y libertades fundamentales".

\footnotetext{
${ }^{68}$ Resolución del Parlamento Europeo sobre la protección de las minorías y las políticas de lucha contra la discriminación en la Unión Europea ampliada (2005/2008(INI)).

69 Párrafo 7, Resolución de 8 de junio de 2005, DO núm. C 124E, 25 de mayo de 2006, p. 405. En el anterior "Informe Moraes" de 24 de febrero de 2005, se afirmó que "el concepto dista mucho de estar armonizado, ni siquiera en el ámbito de las Naciones Unidas o el Consejo de Europa", mencionando como ejemplo las contradicciones de la práctica relacionada con el Convenio Marco sobre la Protección de las Minorías Nacionales (Cfr. Parlamento Europeo, Provisional, 2005/2008(INI), 24 de febrero de 2005, Proyecto de Informe sobre la protección de las minorías y las políticas de lucha contra la discriminación en la Unión Europea ampliada (2005/2008(INI)), Comisión de Libertades Civiles, Justicia y Asuntos de Interior. Ponente: Claude Moraes, p. 4).
} 
A pesar de todo lo expuesto hasta ahora, los resultados distan de ser satisfactorios, por lo que el Tratado de Lisboa, firmado el 13 de diciembre de 2007 y que entró en vigor el 1 de diciembre de 2009, ha supuesto un nuevo y necesario impulso en la protección de las minorías cuyo exponencial alcance aun está por obtener. Como consecuencia inmediata, se observa un desarrollo mayor del marco legal de la Unión Europea que debe considerarse, no obstante, altamente meritorio, dado que se ha producido dentro de un clima generalizado de aprehensión legal y político hacia la diversidad y los derechos de identidad grupal. Este avance normativo, equipa mejor a la Unión Europea para desempeñar un papel más receptivo hacia la protección de la diversidad, pero con un alcance limitado por varios aspectos: a) los Tratados de la UE aún no tienen una competencia legal general sobre los derechos de las minorías y no definen los términos relevantes; b) en la práctica, la Unión Europea en sus desarrollos legales, atiende las peticiones de participación en la protección de las minorías europeas al tiempo que atiende diligentemente las preocupaciones sobre el mantenimiento de la soberanía sobre el terreno, dos demandas que a menudo siguen siendo contradictorias en Europa. En otras palabras, estos desarrollos legales, a pesar de abogar por el respeto a la diversidad, buscan preservar el status quo dentro de los estados, impidiendo así que la Unión Europea trabaje hacia una mejor protección de las minorías que el Estado ha excluido dentro de la legislación nacional ${ }^{70}$; y c) la ausencia de una cooperación continuada, real y efectiva entre los Estados.

Con las enmiendas del Tratado de Lisboa, también cobra mayor importancia la dimensión institucional para la igualdad de trato. El artículo 4 (2) del TUE exige que la Unión Europea respete las estructuras de autogobierno regional y local de los Estados miembros, yendo más allá que la ley anterior a Lisboa que únicamente reconocía la importancia de las identidades nacionales de los Estados miembros.

A este marco normativo hay que añadir la mención a la Carta Europea de Derechos Fundamentales de Niza (7 de Diciembre de 2000), que, con valor jurídico vinculante tras su reconocimiento en el Tratado de Lisboa en 2007, contempla expresamente la protección de los derechos de las personas pertenecientes a minorías,

${ }^{70}$ AHMED, T., "The Treaty of Lisbon and Beyond: The Evolution of EU Minority Protection?", European Law Review, Vol. 38, n¹, 2013, págs. 30-51. Ahmed afirma que no solo los desarrollos legislativos de los Estados miembros no crean nuevos derechos de minorías, sino que el compromiso de la Unión Europea con el CEDH también apoya esta postura ya que el CEDH también se muestra reacio a interferir profundamente con las políticas de los estados hacia las minorías. "Por lo tanto, la protección de las minorías de la UE se basa en modelos de protección de las minorías adoptados por los Estados miembros de la Unión Europea. Cuando un Estado miembro ofrece protección a las minorías, la deficiencia en la base subyacente de las disposiciones legales de la UE o la jurisprudencia de la UE puede pasar inadvertida. Sin embargo, cuando los dos intereses compiten, es decir, los Estados miembros no brindan la protección relevante a las minorías, entonces las partes de las partes de las partes de las partes de las partes de los Estados Unidos son las siguientes: 130 Lo que permiten a la Unión Europea dirigir direcciones (basta el próximo) para su gestión en la protección de las minorías europeas, que responden de manera simultánea a las preocupaciones del Estado por el mantenimiento de la soberania en el campo, dos demandas que con frecuencia siguen siendo contradictorias en Europa. Este escenario plantea serias dudas sobre cualquier perspectiva de una evolución significativa de la protección de las minorías en la UE (...)". 
prohibiendo "toda discriminación, y en particular la ejercida por razón de sexo, raza, color, orígenes étnicos o sociales, características genéticas, lengua, religión o convicciones, opiniones políticas o de cualquier otro tipo, pertenencia a una minoría nacional, patrimonio, nacimiento, discapacidad, edad u orientación sexual" (art. 21).

III.A.7. La Organización para la Seguridad y la Cooperación en Europa (OSCE).

La Organización para la Seguridad y la Cooperación en Europa (OSCE) se encarga de alcanzar compromisos políticos para solucionar conflictos o evitar conflictos potenciales, para lo que dispone de un órgano encargado de abordar las tensiones étnicas, así como prevenir y evitar conflictos en cuestiones relativas a las minorías nacionales: el Alto Comisionado para las Minorías Nacionales. Basándose en la experiencia, el Alto Comisionado publica Recomendaciones y Directrices temáticas en las que asesora acerca de problemas y prácticas recomendables comunes ${ }^{71}$.

No obstante, la OSCE tampoco ha definido el término minoría, aunque Max Van Der Stoel (primer Alto Comisionado) manifestó al respecto que la existencia de minorías nacionales "es una cuestión de hecho, no de definición", por lo que su reconocimiento derivaría de su propia existencia, aportando una conceptualización a partir de esta realidad consciente: "minoría nacional es un grupo con una identidad lingüística, étnica o cultural que se diferencia de la mayoría y que, no solo busca conservar su identidad sino que también intenta obtener una mayor expresión de esa identidad"72.

A esto hay que añadir que en 1990, la Conferencia sobre la dimensión humana recogió en su párrafo 32 que el pertenecer a una minoría nacional constituye una opción individual que no se puede traducir en ningún tipo de desventaja para ésta. Asimismo, reconoció el derecho de las "personas pertenecientes a minorías nacionales" a "expresar, preservar y desarrollar libremente su identidad étnica, cultural, lingüistica o religiosa y de mantener y desarrollar su cultura en todos sus aspectos, libres de cualquier tentativa de asimilación contra su voluntad". Incluso hizo mención del modo en que pueden "ejercer y disfrutar" de sus derechos, esto es, "individualmente, así como en comunidad con otros miembros de su grupo".

Además, el texto decreta que ninguna de sus disposiciones podrá interpretarse de manera que faculte ningún derecho a emprender actividades o llevar a cabo cualquier acción en contravención de los propósitos y principios de la Carta de las Naciones Unidas, "u otras obligaciones dimanantes del derecho internacional y las disposiciones del Acta Final, incluido el principio de la integridad territorial de los Estados" (párrafo 37). Hay que puntualizar que, aunque los acuerdos a los que llega la OSCE son normalmente políticos y carecen, por tanto, de vinculación jurídica, de ellos deriva una fuerte obligatoriedad moral que suele ser tenida en consideración por parte de los Estados, por lo que es un órgano que cumple una muy valorable función.

71 www.osce.org

72 Keynote address at the opening of the OSCE Minorities Seminar in Warsaw in 1994. 


\section{III.B. Balance sobre los instrumentos europeos}

Se hace dolorosamente patente como, a pesar de todos los esfuerzos realizados en la materia de protección de las minorías, seguimos sin contar con una definición internacionalmente global y consensuada sobre qué grupos la conforman o sus rasgos diferenciadores definitivos, lo que sigue dificultando la cuestión. Seguramente, con tal omisión se pretende huir de una definición estricta y limitada que deje fuera a colectivos que la doctrina o la realidad social exijan ver incluidos en sus parámetros en algún momento, pero también es consecuencia de una confusión aún no despejada respecto al fenómeno en sí. Ciertamente, solo echar un somero vistazo a la complejidad de la realidad social e histórica puede hacer que nos inclinemos a entender y transijamos en la ausencia de un concepto consensuado. Pero no se puede ignorar el hecho que la ambigüedad en la identificación del sujeto de derecho de las normas convierte toda regulación en prácticamente inaplicable o tiene como consecuencia una inseguridad jurídica exponencialmente perjudicial al potencial normativo que debe desplegar. En este sentido y sin que aporte más que confusión al respecto, el TEDH ha reconocido que si bien es obvia la existencia de "... un emergente consenso internacional... reconociendo las necesidades especiales de las minorías y una obligación de proteger su seguridad, identidad y estilo de vida", también declara no estar "convencido de que el consenso sea suficientemente concreto para que se deriven orientaciones con respecto a los estándares que los Estados contratantes consideran deseable en una situación particular"73.

Pese a los esfuerzos desarrollados a nivel normativo y doctrinal, no se han producido resultados satisfactorios. No olvidemos que la falta de limitación conceptual se ha solventado desde el nivel internacional con el reconocimiento de un amplio amplísimo en realidad - "margen de apreciación" a los Estados a la hora de identificar a los colectivos merecedores de protección, lo que se traduce en que son los Estados quienes por medio de declaraciones o de desarrollos normativos de carácter interno (y siempre según la voluntad política, social y económica del momento) condiciona la efectividad de la protección. Es este un importantísimo "filtro" negativo a salvar: como mínimo deberíamos contar con una definición general y consensuada como primer y fundamental paso que acote la ambigüedad en la que se ampara el no reconocimiento de los grupos a proteger.

73 STEDH Chapman v. United Kingdom, no 27238/95 de 18 de enero de 2001. Al respecto, el presidente del Tribunal Europeo de Derechos Humanos (TEDH), Guido Raimondi, ha instado a avanzar en la protección de las minorías ante la diversidad cultural existente, aunque ha reconocido los márgenes de apreciación jurisdiccional de cada país de la Unión Europea al no haber consensos en todos los asuntos. Guido Raimondi pronunció el 23 de febrero de 2018 una conferencia en el marco del III Seminario Tribunal Constitucional-Tribunal Supremo en la sede del primer órgano, a la que asistieron los presidentes de estas dos instituciones, Juan José González Rivas y Carlos Lesmes, respectivamente. Disponible en https://www.eldiario.es/politicalpresidente-TEDH-proteger-consensos-UE_0_743326261.html 


\section{RECONOCIMIENTO Y PROTECCIÓN DE LAS MINORÍAS EN ESPAÑA}

Nuestro ordenamiento ha seguido la senda común y no ha aportado una definición. Tampoco existe una normativa general que aborde el fenómeno de la diversidad en conjunto ${ }^{74}$, aunque se han promulgado disposiciones especiales cuyo ámbito de aplicación es la comunidad roma o gitana. No obstante, es evidente que en nuestro país coexisten otros grupos diferenciados de base lingüística y religiosa.

Pese a ello, la ausencia de un marco jurídico interno general no significa que nuestro ordenamiento no disponga de herramientas jurídicas para la protección de estos colectivos. Nuestra Constitución, al igual que el resto de Constituciones de nuestro entorno, cuenta con toda una serie de preceptos que constituyen un marco general de protección en el contexto de la consagración de valores de igualdad y libertad, y, por lo tanto, recogen la prohibición de todo tipo de discriminación. Ya desde el Preámbulo, nuestra Carta Magna consagra como uno de sus principales objetivos el "proteger a todos los españoles y pueblos de España en el ejercicio de los derechos bumanos, sus culturas y tradiciones, lenguas e instituciones". Y a lo largo de todo el cuerpo constitucional se van garantizando derechos que redundan en la protección de los miembros de los grupos: el art. 1.1 (consagra la igualdad como uno de valores superiores del ordenamiento jurídico), el art. 2 (reconoce y garantiza el derecho a la autonomía de las nacionalidades y regiones), el art. 3 (reconoce la diversidad lingüística y garantiza su protección), el art. 9.2 (establece el mandato a los poderes públicos para que la libertad y la igualdad del individuo y de los grupos en que se integra sean reales y efectivas), el art. 10.2. (los derechos fundamentales se interpretarán de conformidad con la Declaración Universal de Derechos Humanos y los tratados y acuerdos internacionales sobre las mismas materias ratificados por España), el art. 14 (consagra la igualdad de todo ser humano y la prohibición de discriminación por razón de sexo, raza, etc.), los artículos del 15 al 29 (garantizan los derechos fundamentales y libertades públicas), o el art. 43 (reconoce el derecho a la protección a la salud), entre otros.

A nivel internacional, España ha ratificado diligentemente los textos internacionales de la ONU, así como de la Unión Europea y el Consejo de Europa (con la excepción de la Carta Social Europea revisada de 1996 y del procedimiento de reclamaciones colectivas, todavía pendientes de aceptación, como se ha analizado más arriba. Sin embargo, ha mostrado una tendencia a restringir todo lo posible la aplicación de sus disposiciones. Así se puede constatar, por ejemplo, en el seguimiento del Pacto de Derechos Económicos, Sociales y Culturales, donde nuestro país sólo ha atendido a las cuestiones referentes con la lucha contra la discriminación de la pobla-

74 JIMÉNEZ PIERNAS ha señalado que la cuestión en nuestro país se ha "desatendido o tratado con ligereza a pesar de que la inercia de nuestro sistema constitucional apunta en esta dirección" ("Prólogo" a la obra de ARP, "Las Minorías nacionales y su protección en Europa", Centro de Estudios Políticos y Constitucionales, Madrid, 2008)

N. ${ }^{\circ} 106$, septiembre-diciembre 2019, págs 199-250 
ción gitana y sus derechos culturales, sin conferir entidad a otros grupos minoritarios $^{75}$. En la misma línea, en los Informes presentados con ocasión de los sucesivos ciclos de control (2010 y 2015) que se han desarrollado en el marco del Examen Periódico Universal, España sólo menciona a la población roma/gitana. Solo después de las numerosas recomendaciones recibidas ha aceptado considerar aspectos relacionados con la lucha contra la discriminación de las minorías religiosas.

En cuanto al Convenio Marco del Consejo de Europa para la Protección de las Minorías Nacionales, España ratificó el texto en 1995. No obstante, la aplicación de dicho Convenio también ha sido restrictiva como resultado del limitado reconocimiento en cuanto a su ámbito de aplicación. El Ejecutivo español se ha mostrado reacio a admitir que existan minorías nacionales en su territorio, hasta el punto de que, aunque el Convenio llega a ser aplicado limitadamente a la comunidad gitana o romaní, para el Gobierno español esto no significa que asuma su consideración como minoría nacional ${ }^{76}$, lo que supone una paradoja. De hecho, de forma reiterada el Gobierno español ha declarado "que no existen nuevas circunstancias que permitan concluir que los mecanismos compensatorios de protección del Convenio Marco deberían aplicarse a otros individuos o grupos que no sean la población gitana" 77 . Y esto aun cuando anteriormente, en lo que ha resultado una afirmación anecdótica, cedió ante las sugerencias planteadas por el Comité Consultivo, admitiendo que estaría en condiciones de asumir la aplicación del Convenio Marco en relación con otras minorías ${ }^{78}$. No debemos olvidar que, en virtud del Convenio, cada Estado puede determinar libremente qué grupos constituyen su marco de aplicación ${ }^{79}$.

75 Comité de Derechos Económicos, Sociales y Culturales, $48^{\circ}$ período de sesiones, 30 de abril a 18 de mayo de 2012, Aplicación del Pacto Internacional de Derechos Económicos, Sociales y Culturales, Examen de los informes presentados por los Estados partes en virtud del artículo 16 del Pacto Internacional de Derechos Económicos, Sociales y Culturales, Adición, Respuestas del Gobierno de España a la lista de cuestiones (E/C.12/ESP/Q/5) que deben abordarse al examinar el quinto informe periódico de España (E/C.12/ESP/5)[1 de marzo de 2012], Doc. UN, E/C.12/ESP/Q/5/Add.1, 28 de marzo de 2012, pp. 6-7 y 50-51.

${ }^{76}$ Comments of the Government of Spain on the opinion of the Advisory Committee on the implementation of the Framework Convention for the Protection of National Minorities in Spain, Documento GVT/COM/INF/OP/I(2004)004, recibido el 10 de junio de 2004; publicado el 30 de septiembre de 2004.

77 Comentarios del Gobierno de España acerca del cuarto dictamen del Comité Consultivo sobre la implementación del Convenio Marco para la Protección de las Minorías Nacionales de España, en base al cuarto informe presentado por España al Consejo de Europa y en base a la visita a España del Comité Consultivo en julio de 2014. (Disponible en http://www.mscbs.gob.es/ssi/familiasInfancia/ inclusionSocial/poblacionGitana/docs/4th_Com_Spain__ES.pdf)

78 España ha admitido que estaría en condiciones de asumir la aplicación del Convenio en relación con la población bereber, aun aludiendo a "problemas técnicos" derivados de la falta de normalización lingüística del "dialecto chelha”. No obstante, no se ha llegado a aprobar medida alguna al respecto, lo que ha provocado que insistentemente el Comité Consultivo solicite la aplicación de sus disposiciones a esta minoría(Comentarios de España, 10 de junio de 2004).

79 Anteriormente, el Comité Consultivo ha advertido que, aunque España no admita otros grupos diferentes a los roma como destinatarios de la Protección que arbitra el Convenio, es fácilmente 
Igualmente, el texto otorga un margen a los Estados para adaptar sus disposiciones a las condiciones específicas de cada Estado, a través de la legislación nacional y las políticas gubernamentales ${ }^{80}$. Asimismo, los grupos pueden optar por ser protegidos por el Convenio o no (artículo 3), lo que en la práctica ha significado que la comunidad gitana se encuentre amparada por el Convenio, mientras que los gallegos, catalanes y vascos, han manifestado su deseo de que no se le aplique dicha protección ${ }^{81}$. No obstante, dejando aparte estas consideraciones, un amplio sector doctrinal señala que es perfectamente factible que el Convenio Marco sea aplicado en nuestro país a otros colectivos culturales, lingüísticos o religiosos que en la actualidad no gozan de su protección. El Convenio nace con la finalidad de constituir un instrumento garantizador de derechos humanos que favorezca una tolerancia plena hacia una diversidad que avanza y que supone un exponente real en las sociedades europeas. Aunque se argumente desde una visión un tanto limitada que los valores jurídicos vigentes en las Constituciones, como la igualdad, imposibilita este tipo de propuestas normativas (y una interpretación de esta igualdad ante la ley que es inflexible y formalista, por la que se abogaría que ante las diferencias, el trato jurídico sea igual), no se puede dejar de lado una realidad que se impone por sí misma como argumento valedero. No, cuando esto nos llevaría a aceptar que un instrumento normativo internacional y expreso que "perfecciona" la efectividad real de los máximos pronunciamientos a nivel constitucional sea obviado. A esto puede añadírsele que, al constituir un Documento ratificado por España, la aplicación debe ser coronado con un esfuerzo que suponga la determinación de los grupos de aplicación.

A estos argumentos tendría que sumársele otro que debe ser tenido en cuenta en el momento crucial de determinar los grupos que constituyen el ámbito de aplicación de las normas. Este argumento, no por obvio, debe dejar de mencionarse y evaluarse con precisión: los colectivos deben necesitar de la aplicación niveladora de la norma como consecuencia de la existencia de una situación tal que no exista una plena y efectiva igualdad entre las personas pertenecientes a la minoría nacional y las pertenecientes a la mayoría. Con ello, el paso previo, necesariamente, consiste en evaluar debidamente las condiciones específicas de las personas pertenecientes a las minorías nacionales con el objetivo de proporcionar soluciones certeras.

En esta situación, de manera inequívoca e indiscutible, se encuentra el colectivo roma/gitano en nuestro país, por lo que este estudio prosigue centrándose en ellos.

\footnotetext{
imaginable el considerar a otros grupos merecedores de la protección. A este argumento, el Gobierno español ha respondido que no es necesario incluir a las minorías lingüísticas dentro del ámbito de aplicación del Convenio, al contar ya "con la protección debida dentro del propio marco jurídico del Consejo de Europa, tales como la Carta Europea de Lenguas Regionales y Minoritarias" ( $2^{a}$ opinión emitida por el Comité Consultivo en febrero de 2007)

${ }^{80}$ EIDE, A., "The Framework Convention in Historical and Global Perspective", en Weller, M. (ed.), "The Rights of Minorities", Oxford, 2005, págs. 25-47.

${ }^{81}$ ARP, B., "La aplicación del Convenio-Marco para la protección de las minorías nacionales en España: el segundo ciclo", Revista Española de Derecho Internacional, Vol. 2-LX, 2008, pp. 689-695.
} 


\section{IV.A. Comunidad roma/gitana}

La comunidad roma/gitana constituye un colectivo asentado por todo el territorio de la Península desde hace varios siglos, con una cultura propia muy marcada, y que constituye el dos por ciento de la población total ${ }^{82}$. Entre sus reivindicaciones no se encuentra el reclamar para si un territorio o Estado propio, sino condiciones de respeto a su diversidad cultural y una efectiva igualdad a nivel social y económico.

España firmó y ratificó el Convenio Marco para la Protección de las Minorías Nacionales sin hacer ninguna Declaración adicional. El Gobierno español remitió el primer Informe Nacional al Consejo de Europa tardíamente, en noviembre del 2000 , centrándose exclusivamente en la comunidad gitana o roma. Con posterioridad, el Comité Consultivo preguntó al Gobierno español acerca del estatus de la minoría roma, así como por la relación entre los “pueblos” y las "nacionalidades” de España con el texto del Convenio Marco. La consulta se origina por la constatación de los variados términos que son utilizados en la Constitución de 1978 para designar a la población española en su conjunto (“el pueblo español”, en el artículo 1.2; "todos los españoles” en el Preámbulo, "la nación española” en el Preámbulo y en el artículo 2). En la consulta, el Comité señala que "(...) desde el punto de vista legal, los gitanos (roma) no son reconocidos ni como un "pueblo" ni como minoría nacional". La respuesta española es la siguiente: "no hay en la realidad jurídico-política española un concepto de pueblo como una entidad con características diferenciadas en cuento a etnia, religión o identidad. Los diferentes pueblos son identificados en tanto que constituyen la base de población en las distintas comunidades autónomas, con diferentes tradiciones culturales $y$, a veces, una lengua propia (...) pero que, en su conjunto, constituyen un único pueblo, el pueblo español sujeto de la soberanía (...)". Prosigue argumentando el hecho de limitar su Informe nacional a la comunidad roma afirmando que, "aunque no constituye una "minoría nacional", es la única que podría de alguna manera estar integrada en el espíritu del Convenio Marco". Asimismo, los "(...) ciudadanos españoles de etnia roma son ciudadanos de pleno derecho (...) así pues ni necesitan ser ni podrían ser reconocidos como una "minoría nacional", porque es legalmente imposible clasificarlos como tales" $"$.

82 www.msssi.gob.es: "La población gitana está presente en España desde el siglo XV y su trayectoria bistórica ha estado marcada, igual que en el resto de Europa, por persecuciones, intentos de asimilación y procesos de exclusión social. Actualmente, la población gitana española se calcula en alrededor de 725.000-750.000 personas, siendo éstas las cifras relativas a España que han utilizado las instituciones europeas en sus cálculos sobre la población romani para el conjunto de Europa. No obstante, hay que mantener cierta cautela con respecto a este dato pues no se conoce con exactitud el tamaño real de esta población (...). Sin perjuicio de reconocer estas limitaciones (...) se tiene un conocimiento preciso de que la población gitana se encuentra distribuida por todo el territorio del Estado, siendo su presencia más destacada en Andalucía, donde residen en torno al cuarenta por ciento de las gitanas y gitanos españoles, así como en Cataluña, Valencia y Madrid".

83 Comentarios presentados por el Gobierno español en respuesta a la opinión del Comité asesor sobre la implementación en España del Convenio Marco para la Protección de las Minorías Nacionales, 10 de junio de 2004. 
Tras el intercambio de comunicaciones entre el Comité Consultivo del Convenio y el Gobierno español, la Resolución del Comité de Ministros del Consejo de Europa sobre la implementación por parte de España del Convenio Marco de 30 de septiembre de 2004, adopta la siguiente conclusión: "debería prestarse atención especial a la promoción de la cultura, lengua y tradiciones roma, de cara a facilitar una mejor integración de los roma en la sociedad española (...)".

Las presiones recibidas en este sentido provocaron que en poco tiempo y a nivel interno se produjeran avances normativos. Se aprueba el Real Decreto 891/2005, de 22 de julio, que crea y regula el Consejo Estatal del Pueblo Gitano cuya finalidad primordial es "promover la participación y colaboración del movimiento asociativo gitano en el desarrollo de las políticas generales y en el impulso de la promoción de la igualdad de oportunidades $y$ de trato dirigidos a la población gitana" (art. 2.2). El Consejo Estatal del Pueblo Gitano es un órgano colegiado adscrito al Ministerio de Trabajo y Asuntos Sociales a través de la Secretaría de Estado de Servicios Sociales, Familias y Discapacidad (art. 1) con amplias funciones entre las que se encuentran:

a) Proponer y asesorar sobre medidas para la promoción integral de la población gitana, dentro del marco de competencias de la Administración General del Estado, incorporando el principio de transversalidad.

b) Asesorar sobre el diseño, elaboración, evaluación y seguimiento de los planes de desarrollo gitano.

c) Presentar iniciativas en relación con los fondos para programas destinados a la población gitana y a los criterios de distribución.

d) Emitir dictámenes e informes sobre aquellos proyectos normativos y otras iniciativas relacionadas con los fines del Consejo que se sometan a su consideración y que afecten a la población gitana y, en especial, en el desarrollo de la normativa de igualdad de oportunidades y de igualdad de trato.

e) Promover la comunicación y el intercambio de opiniones e información entre la población gitana y la sociedad en general.

f) Canalizar las peticiones y propuestas de las organizaciones no gubernamentales cuya actividad tenga relación con la población gitana y con la superación de desigualdades, con vistas a facilitar la convivencia y cohesión social entre la ciudadanía gitana y la sociedad en general.

g) Recabar información sobre normativa, programas y actividades que lleve a cabo la Administración General del Estado respecto a la comunidad gitana, ampliando dicha información a normativas y actividades de las Administraciones autonómicas y locales y de los organismos internacionales.

h) Elaborar un informe periódico en el que se incluyan propuestas dirigidas a mejorar las políticas sociales con la comunidad gitana.

i) Desarrollar cuantas otras funciones se le atribuyan y resulten de la aplicación de los planes de desarrollo gitano y aquellas que, en el marco de sus competencias, se atribuyan al Consejo por alguna disposición legal o reglamentaria. 
Con posterioridad, el Real Decreto 1262/2007 regula el Consejo para la Promoción de la Igualdad de Trato y no Discriminación de las Personas por el Origen Racial o Étnico, organismo creado por el artículo 33 de la Ley 62/2003, de 30 de diciembre, de Medidas fiscales, administrativas y del orden de lo Social. Entre sus funciones corresponde la promoción del principio de igualdad de trato y no discriminación, de las personas por su origen racial o étnico, en la educación, la sanidad, las prestaciones y los servicios sociales, la vivienda, y en general, la oferta y el acceso a cualesquiera bienes y servicios, así como el acceso al empleo. Para el cumplimiento de sus fines, el Consejo tiene atribuidos competencias de tipo asistencial a las víctimas de discriminación directa o indirecta por razón del origen racial o étnico, así como la potestad de realizar análisis y estudios y publicar informes independientes sobre la discriminación de las personas y promover medidas que contribuyan a la igualdad de trato y a la eliminación de la discriminación. Estas facultades son ejercidas con plena autonomía funcional y con el apoyo del Observatorio Español del Racismo y la Xenofobia.

Todos los avances reglamentarios mencionados así como las políticas activas implementadas en los diferentes niveles de la Administración son los que pone en valor el Estado español en los comentarios presentados al Consejo de Europa respecto al cuarto Dictamen del Comité Consultivo sobre la implementación del Convenio Marco en base al Cuarto Informe y a la visita a España del Comité Consultivo, en julio de $2014^{84}$. El Gobierno comienza agradeciendo los "elogios" por parte del Comité Consultivo referentes a estas iniciativas "así como el reconocimiento del progreso que ha experimentado la población gitana en aspectos fundamentales relacionados con la inclusión social, tales como educación, salud, empleo y vivienda, a pesar de los efectos de la crisis económica y de la brecha existente respecto a la situación de la mayoría de la población". A esto añade información adicional y varias aclaraciones para que también le sean valoradas, como la puesta en marcha de medidas dirigidas a aumentar el conocimiento sobre el Convenio Marco y el apoyo activo que se brinda desde el Ministerio de Sanidad, Servicios Sociales e Igualdad al Consejo Estatal del Pueblo Gitano. Este apoyo al Consejo Estatal del Pueblo Gitano se ha concretado en la participación activa del órgano en una de las reuniones del Grupo de Cooperación Técnica para la inclusión de la Población Gitana en las Comunidades Autónomas con las autoridades locales con la finalidad de que realice propuestas específicas a los siguientes documentos, entre otros: a) el Plan operativo de Estrategia Nacional para la Inclusión Social de la Población Gitana en España 2014-2016; b) el Acuerdo de Asociación de Fondos Estructurales y de Inversión Europeos 2014-2020; c) la Propuesta de indicadores por la Agencia de la UE para los Derechos Fundamentales, y d) la Guía de recomendaciones de aplicación del principio horizontal de igualdad no discriminación en Fondos Estructurales y de Inversión Europeos 2014-2020 elaborado por el Instituto de la Mujer y para

\footnotetext{
${ }^{84}$ http://www.mscbs.gob.es/ssi/familiasInfancia/inclusionSocial/poblacionGitana/docs/4th_Com_ Spain_ES.pdf
} 
la Igualdad de Oportunidades del Ministerio de Sanidad, Servicios Sociales e Igualdad, entre otros documentos.

No obstante, el Gobierno de España no pierde la oportunidad de reafirmarse en su postura de que no existen nuevas circunstancias que permitan concluir que los mecanismos compensatorios de protección del Convenio Marco deberían aplicarse a otros individuos o grupos que no sean la población gitana. Por tanto, aunque el Convenio Marco constituye una “oportunidad” constante que presiona hacia la adopción de un necesario desarrollo de las líneas normativas y de actuación que proporcionan resultados positivos, la potencialidad en su aplicación es restringida hasta el desaprovechamiento. La solución pasaría por la evolución hacia una firme actitud política de realización efectiva del respeto de las diversidades identitarias sin distinción y en compromiso profundo con los derechos humanos.

Por otro lado y en el marco de la Unión Europea, el 5 de abril de 2011 la Comisión Europea publicó la "Comunicación sobre el Marco de la Unión Europea (UE) para las Estrategias Nacionales de Inclusión de la Población Gitana hasta 2020”, donde se establece por primera vez un marco general y común para el desarrollo de medidas y políticas en el ámbito nacional a partir de objetivos compartidos por todos los Estados miembros de la Unión Europea. Este nuevo Marco Europeo obligaba a los Estados miembros, en proporción a su número de población gitana, a presentar sus propias Estrategias Nacionales antes de finales de ese año en ámbitos que abarcaban la educación, el empleo, la salud y la vivienda. El gobierno español, en cumplimiento de esta obligación, presentó a la Comisión Europea en Marzo de 2012 la Estrategia Nacional, donde establece el marco de trabajo para la inclusión de la población gitana ${ }^{85}$.

La Estrategia define unos objetivos a alcanzar en el año 2020, así como metas intermedias para el año 2015, en cuatro áreas clave: la educación, el empleo, la vivienda y la salud ${ }^{86}$. La Estrategia tiene en cuenta la alta dispersión geográfica de la población gitana por lo que no adopta un enfoque territorial específico. Aun así, muchas de las líneas de actuación previstas (especialmente las que corresponden a los ámbitos de educación, salud y vivienda), se concentran en aquellos barrios o zonas urbanas en los que hay una mayor prevalencia de población gitana. No obstante, hay que tener en cuenta que la Estrategia se basa, tanto en el acceso de la población gitana a medidas y programas de carácter general (no exclusivamente concebidos para población gitana), como en el desarrollo de medidas específicas. En consecuencia, la financiación

${ }^{85}$ El Consejo de Ministros aprobó el 2 de marzo de 2012 la Estrategia Nacional para la Inclusión Social de la Población Gitana en España 2012-2020.

${ }^{86}$ www.msssi.gob.es: "Hay varios objetivos nacionales de la Estrategia Europea 2020 de particular relevancia en términos de inclusión social: el aumento de la tasa de empleo entre 20-64 años (de 62,5\% a 66\% en 2015 y 74\% en 2020), el aumento de la tasa de empleo femenino entre 20-64 años (de 55,8\% a 68,5\% en 2020), la reducción de la tasa de abandono escolar prematuro (de 31,2\% a 23\% en 2015 y 15\% en 2020); el aumento de la proporción de población entre 30-34 años con estudios terciarios (de 39,4\% a $41 \%$ en 2015 y 44\% en 2020). Por último, España adopta como objetivo reducir entre 1.400 .000 y 1.500 .000 (en el período 2009-2019) el número de personas en riesgo de pobreza y exclusión social (de 10,6 a 9,1-9,2 millones)".

N. ${ }^{\circ} 106$, septiembre-diciembre 2019, págs 199-250 
de las acciones necesarias para la consecución de los objetivos procederá de dos vías: a) las partidas presupuestarias de políticas, planes y programas universales en cada área referida en las líneas de actuación, de las que se beneficiará la población gitana junto con el resto de ciudadanos; y b) las partidas presupuestarias específicas de las que se beneficiará preferentemente la población gitana ${ }^{87}$.

Por otra parte, la comunidad roma/gitana dispone de una lengua propia, cuya promoción y defensa ha sido hasta la fecha notablemente débil o inexistente. Recordemos que la Carta Europea de las Lenguas Regionales y Minoritarias fue firmada por España el 5 de noviembre de 1992 y ratificada el 2 de febrero de 2001 y que en la Declaración que acompañaba la ratificación de la Carta, España declara que "se entiende por lenguas regionales o minoritarias las lenguas reconocidas como oficiales en los Estatutos de Autonomía de las Comunidades Autónomas del País Vasco, Cataluña, Baleares, Galicia, Valencia y Navarra. Al mismo tiempo, España declara, a los mismos fines, que por lenguas regionales o minoritarias se entienden aquellas protegidas y apoyadas por los Estatutos de Autonomía en los territorios en los que éstas son tradicionalmente habladas".

En el primer informe que España envía al secretario general del Consejo de Europa en noviembre de 2002 se hace una sucinta mención a la lengua romaní: "El instrumento de ratificación de España de la carta Europea de lenguas regionales o minoritarias no hace referencia alguna a las lenguas referidas en la carta como "lenguas no territoriales" en tanto que la única lengua con esta característica a la que la carta podría ser aplicada es el romaní, hablada por personas de origen gitano, aunque apenas 100 personas utilizan esta lengua en España, esto es el 0,01\% del número total de personas de este grupo que viven en España, mientras que en Alemania y Francia el porcentaje es del 70\%”. No obstante, a esto se puede objetar que, tal y como ha señalado el Parlamento Europeo, las dos funciones principales de la Carta Europea de las Lenguas Regionales o Minoritarias es precisamente y por un lado, la protección de las lenguas en peligro de desaparición, y por otro lado, constituir un eficaz mecanismo de protección de las minorías, dos puntos que son especificados en los criterios de Copenhague como obligatorios para la adhesión de los Estados a la Unión Europea. Asimismo, el Parlamento ha manifestado que todas las lenguas de Europa son iguales en valor y dignidad, situando las lenguas amenazadas de desaparición como parte del patrimonio cultural europeo y no como un vehículo para aspiraciones políticas, étnicas o territoriales. "Todas las lenguas, también las amenazadas de desaparición, reflejan unos saberes históricos, sociales y culturales y una mentalidad y una forma de creatividad y de crear que contribuyen a la riqueza y la diversidad de la Unión Europea y a los fundamentos de la identidad europea; que, por ello, la diversidad lingüística y la presencia de lenguas amenazadas en un país deben considerarse un activo en lugar de una carga, y conviene respaldarlas y fomentarlas como tales"88.

${ }^{87}$ Estrategia Nacional para la Inclusión Social de la Población Gitana en España 2012-2020, en: https://www.mscbs.gob.es/ssi/familiasInfancia/inclusionSocial/poblacionGitana/docs/ EstrategiaNacionalEs.pdf

88 Resolución del Parlamento Europeo, de 11 de septiembre de 2013, sobre las lenguas europeas amenazadas de desaparición y la diversidad lingüística en la Unión Europea (2013/2007(INI). 
No obstante, en la efectividad del reconocimiento de la protección de la comunidad roma (y del resto de minorías), no debemos obviar la importancia crucial de la regulación a nivel regional. Los Estatutos de Autonomía y su legislación de desarrollo son piezas fundamentales, puesto que, en la asunción de las competencias por parte de las Comunidades Autónomas y del Estado que se deriva de la aplicación de los artículos 148 y 149 de la Constitución, los Estatutos de Autonomía suelen tener la competencia exclusiva en algunas materias cruciales para el tema que nos ocupa, como por ejemplo, las que inciden sobre los derechos sociales, aun cuando alguna de éstas, como la educación, son tan solo de desarrollo legislativo y ejecución de la regulación básica del Estado.

Al respecto, se observa una tendencia al alza en los denominados Estatutos de autonomía "de nueva generación" (esto es, los adoptados a partir de 2006) a incluir de forma expresa a la comunidad gitana en sus disposiciones. Así, el Estatuto de Autonomía de Andalucía (Ley Orgánica 2/2007, de 19 De Marzo, de Reforma del Estatuto de Autonomía para Andalucía) asigna a la Comunidad Autónoma la función de garantizar el pleno respeto a las minorías que residan en su territorio en el artículo 9 (apartado 2), para a continuación recoger en el artículo 10 los objetivos básicos de la Comunidad Autónoma, entre los que se encuentra "la promoción de las condiciones necesarias para la plena integración de las minorias y, en especial, de la comunidad gitana para su plena incorporación social" (10.3.21%).

Por su parte, el Estatuto de Cataluña incluye también una referencia expresa a la comunidad gitana en su Artículo 42, dedicado a la cohesión y el bienestar sociales. “(... 7. Los poderes públicos deben velar por la convivencia social, cultural y religiosa entre todas las personas en Cataluña y por el respeto a la diversidad de creencias y convicciones éticas y filosóficas de las personas y deben fomentar las relaciones interculturales mediante el impulso y la creación de ámbitos de reconocimiento recíproco, diálogo y mediación. También deben garantizar el reconocimiento de la cultura del pueblo gitano como salvaguarda de la realidad histórica de este pueblo".

El Estatuto de Castilla y León (Ley Orgánica 14/2007, de 30 de noviembre, de reforma del Estatuto de Autonomía de Castilla y León), en el CAPÍTULO IV, dedicado a los Principios rectores de las políticas públicas, consagra en el artículo 16. $23^{\circ}$ "(...) La no discriminación y el respeto a la diversidad de los distintos colectivos étnicos, culturales y religiosos presentes en Castilla y León, con especial atención a la comunidad gitana, fomentando el entendimiento mutuo y las relaciones interculturales".

El Estatuto de Autonomía de Aragón (Ley Orgánica 5/2007, de 20 de abril, de reforma del Estatuto de Autonomía de Aragón), después de que en el primer apartado del artículo 23 se establezca el mandato a los poderes públicos de promover y garantizar "un sistema público de servicios sociales suficiente para la atención de personas y grupos, orientado al logro de su pleno desarrollo personal y social, así como especialmente a la eliminación de las causas y efectos de las diversas formas de marginación o exclusión social, garantizando una renta básica", el segundo apartado establece que los "poderes públicos 
aragoneses promoverán las condiciones necesarias para la integración de las minorías étnicas y, en especial, de la comunidad gitana".

Asimismo, algunos Gobiernos autonómicos han puesto en marcha planes de acción específicos para la población gitana, como el País Vasco ${ }^{89}$, Cataluña ${ }^{90}$, Extremadura $^{91}$ o Navarra ${ }^{92}$. No obstante, destaca el programa de intermediación laboral "Acceder", operativo desde 2000 y que surge con el objetivo de conseguir la incorporación efectiva de la población gitana al mundo laboral. Presente en 14 Comunidades Autónomas y con 51 dispositivos integrados de empleo, tiene su origen en la financiación ofrecida por los Fondos Estructurales en el desarrollo de acciones dirigidas a la activación al empleo (formación vocacional y profesional, prácticas en empresas, mediación entre beneficiarios y empresas). El Programa está implementado por la Fundación Secretariado Gitano.

A todo lo mencionado debemos añadir la existencia de barreras no siempre visibles que obstaculizan exponencialmente la incorporación real del colectivo en la vida económica, cultural y social. Los estereotipos y prejuicios presentes en nuestra sociedad suponen una influencia negativa y decisiva en las relaciones y la convivencia entre personas que pertenecen al colectivo y las que no. En esta cuestión vuelve a ser determinante las sinergias entre las administraciones públicas en todos sus niveles. Pero además, en este sentido se debe tener especialmente presente que la finalidad es la inclusión social y no la asimilación o la absorción del grupo, que llevaría implícita la pérdida de las características culturales que diferencian a la comunidad roma, con el consiguiente empobrecimiento cultural y humano de la sociedad. En esta inclusión la perspectiva debe ser pluridimensional: no solo abarcar el acceso efectivo a recursos, servicios y oportunidades, sino que debe aplicarse en la comprensión (y aquí sí, asimilación) generalizada en la sociedad de los valores igualdad, libertad y la tolerancia. Son estos los pilares indispensables que definen a la sociedad democrática actual, cuya realidad efectiva es la que debe primar en la cotidianidad de la comunidad roma.

\section{CONCLUSIONES}

El Derecho contemporáneo y la doctrina han manifestado un especial interés en el reconocimiento, desarrollo y protección de los grupos, como manifestación de un avance necesario en los sistemas democráticos cuya evolución sigue desbordando las iniciales —ya tan lejanas — concepciones liberales. No obstante, y en puridad, no estamos ante una demanda de adopción o creación de nuevos derechos, diferentes a los ya reconocidos al resto de miembros de la sociedad donde se insertan: de hecho se

89 I y II Plan Vasco para la Promoción Integral y Participación Social del Pueblo Gitano (20042007) y (20072011).

90 I y II Plan Integral del Pueblo Gitano de Cataluña (20052008) y (20092013).

91 Plan Extremeño para la Promoción y Participación Social del Pueblo Gitano (20072013)

92 Plan Integral de Atención a la Población Gitana de Navarra (20112014). 
puede observar como la gran generalidad de los derechos reclamados por los grupos minoritarios o nacionales no difieren de la de los miembros de las, llamémoslas un instante, mayorías. No olvidemos que la especial condición de vulnerabilidad sufrida por motivo de su diversidad es lo que exige que los derechos de éstos (de los que si disfrutan más equitativamente el resto de los individuos) deban ser protegidos con la efectividad real de la que adolecen. $\mathrm{Y}$ es en este punto donde las reivindicaciones pueden parecer más innovadoras: la forma de arbitrar los mecanismos jurídicos y las instituciones necesarias al efecto, deben amoldarse a una nueva situación fáctica que supone un esfuerzo preceptivo e innovador en las sociedades actuales. En este marco normativo, el colectivo puede reivindicar la aceptación general de un carácter diferente en sus relaciones con el Estado, dentro del cual podemos encuadrar las demandas y negociaciones de autonomía de los pueblos indígenas que constituyen el eje central de la manifestación limitada del autogobierno de los pueblos ${ }^{93}$.

No obstante, la realidad se encuentra no solo con los graves obstáculos que se manifiestan en la falta de consenso jurídico ya mencionados, sino con la ausencia de un afirme voluntad política, lo que se traduce en que la realización efectiva del debido respeto de las diversidades identitarias sin distinción y en compromiso profundo con los derechos humanos, se pierda en los recovecos de la oportunidad política más titubeante, más nebulosa. Se debe abogar, sin reservas, por el reforzamiento en la protección y las garantías de las minorías que pasa por el perfeccionamiento y desarrollo de los derechos fundamentales adaptados a las necesidades propias de las minorías. Pero, además, y en paralelo, es preciso abordar dos tareas más en clave interna: a) adoptar las medidas de acción positiva necesarias para el acceso a una igualdad real y efectiva; y b) asumir la necesidad de una concienciación y educación de la sociedad en valores de tolerancia, igualdad, el respecto a la diversidad, así como la solidaridad con la diversidad humana. En definitiva, hablamos de la realización de los valores y principios del Estado democrático.

En cuanto al colectivo roma/gitano, hay que señalar que, aunque en algún grado se ha avanzado en las diferencias entre la situación social y económica del colectivo y el resto de la sociedad a través, fundamentalmente, de las políticas que se han puesto en marcha, la realidad dista de ser la deseada. La propia Estrategia lo precisa perfec-

93 Como experiencia de ejercicio de la autonomía indígena podemos citar la Ley de Derechos de Pueblos y Comunidades Indígenas del Estado de Oaxaca (México), aprobada en 1998. Consta de ocho capítulos que recogen disposiciones generales de los pueblos y comunidades indígenas sobre autonomía, cultura y educación, sistemas normativos internos, mujeres indígenas, recursos naturales y desarrollo. El texto reconoce expresamente la posibilidad de que los pueblos y comunidades adopten libremente las formas de organización social y política que corresponden a su tradición, así como modificarlas según sus sistemas normativos internos, sin más limitación que lo establecido en la Constitución Política Local y las leyes del Estado. ("Los pueblos indígenas en América Latina. Avances en el último decenio y retos pendientes para la garantía de sus derechos", 2014, Documento elaborado por el Centro Latinoamericano y Caribeño de Demografía (CELADE)-División de Población de la Comisión Económica para América Latina y el Caribe (CEPAL), bajo la dirección de Dirk Jaspers Faijer. Disponible en:

https://repositorio.cepal.org/bitstream/handle/11362/37222/S1420521_es.pdf?sequence=1) 
tamente: "la persistencia de prejuicios negativos hacia las personas gitanas en parte de la población española provoca que la población gitana siga siendo uno de los grupos hacia los que mayor rechazo social existe. Efectivamente, la discriminación y el rechazo social hacia el colectivo roma continúa siendo una realidad patente y dolorosa. Esto se refleja en el trato y las manifestaciones cotidianas hacia el colectivo y se profundiza dramáticamente en los ámbitos del empleo, la educación, los servicios y el acceso a la vivienda. Es imperativo persistir y promover las condiciones necesarias para consolidar una mayor presencia e interacción del colectivo en la esfera pública, el desarrollo de mecanismos de detección y denuncia de actuaciones discriminatorias en el acceso al empleo o a la vivienda o en cualquier otro ámbito, así como el fomento y concienciación de la cultura de la tolerancia y la igualdad. Representan éstos auténticos desafíos donde únicamente se puede admitir avanzar y progresar, por el riesgo real de un estancamiento que solo atraería un retroceso que supondría un inadmisible "volver a empezar”. En este aspecto, en España el refuerzo de políticas más agresivas y concluyentes, así como una visión del problema en la que el análisis social y económico y la orientación internacional, tanto a nivel legislativo como jurisprudencial, no se rechace de plano, sino que se estudie y se extraiga la efectividad que la fundamenta, podría auxiliar a unos mejores resultados. En suma, las sinergias entre los instrumentos internacionales (universales y europeos) y las estrategias y acciones normativas desarrolladas en el plano interno (y, en nuestro caso, en el marco de la Constitución y de los nuevos Estatutos de Autonomía) constituyen un reto esencial de constitucionalismo multinivel que se ha pretendido abordar en el presente estudio. 
Title:

The protection of minorities: A challenge under a multi-level constitucionalism perspective

\title{
Summary:
}

I. INTRODUCTION. I.A. The concept of indigenous peoples. I.B. The concept of national minorities. I.C. Ethnic minorities and minorities or indigenous peoples. I.D. Conceptual balance. II. TIPOLOGY OF GROUPS: CLASSIFICATION OF MINORITIES. III. THE LEGAL STATUS OF THE GROUPS. III.A. The International regulatory framework. III.A.1. United Nations: particular reference to the International Covenant on Civil and Political Rights of 1966. III.A.2. The European Convention on Human Rights (The Rome Convention). III.A.3. The European Social Charter. III.A.4. The European Charter for Regional or Minority Languages. III.A.5. The Framework Convention for the Protection of National Minorities. III.A.6. The European Union. III.A.7. The Organization for Security and Co-operation in Europe (OSCE). III.B. Balance on European normative instruments. IV. RECOGNITION AND PROTECTION OF MINORITIES IN SPAIN. IV.A. The Roma/Gypsy community. V. CONCLUSIONS.

\section{Resumen:}

El tratamiento jurídico-constitucional de las minorías y su protección en un contexto estatal donde la mayoría puede anular lo que es diferente a ella, constituye una problemática a afrontar en auge en la realidad multicultural en la que nos desenvolvemos, profundamente influenciada por los avances en política social y una moderna comprensión del sistema democrático. La protección en el marco jurídico-constitucional de estos grupos, la definición del concepto de "minoría" sin que haya sido posible alcanzar un consenso, así como el limitado reconocimiento en España de su realidad, son objeto de análisis en este trabajo.

\begin{abstract}
:
The legal-constitutional approach to minorities and their protection in a state context where the majority may expunge that which is different, constitutes a growing problem to be dealt with in the multicultural reality in which we live, it is strongly influenced by the advances of social policy and a modern understanding of democratic system. The protection in international law framework of these groups, the definition of "minority" although no consensus has been reached so far, as well as the limited recognition in Spain of their reality are object of analysis of this paper.
\end{abstract}




\section{Palabras clave:}

Minorías, pueblos indígenas, comunidad gitana, grupos, Naciones Unidas, Consejo de Europa, definiciones.

\section{Keywords:}

Minorities, indigenous peoples, Roma community, groups, United Nations, Council of Europe, definitions. 